NBER WORKING PAPER SERIES

\title{
SAVING EUROPE?: THE UNPLEASANT ARITHMETIC OF FISCAL AUSTERITY IN INTEGRATED ECONOMIES
}

\author{
Enrique G. Mendoza \\ Linda L. Tesar \\ Jing Zhang \\ Working Paper 20200 \\ http://www.nber.org/papers/w20200
}

\author{
NATIONAL BUREAU OF ECONOMIC RESEARCH \\ 1050 Massachusetts Avenue \\ Cambridge, MA 02138 \\ June 2014
}

We are grateful for the support of the SAFE center at Goethe University under a grant of its program on "Austerity and Economic Growth: Concepts for Europe." Tesar also gratefully acknowledges the Isle de France di Marco Foundation and the Paris School of Economics for their support during the early phases of the project. Christian Proebsting provided excellent research assistance. We are grateful to Philippe Bacchetta, Chris House, Harald Uhlig, and seminar participants at USC, Bilkent University, Indiana University, McGill University and Ohio State, and conference participants at the ECB's Global Research Forum on International Macroeconomics and Finance, the Dec. 2013 NBER Macro within and across Borders Conference, and the 2013 CIREQ-ENSAI Dynamic Macro Workshop for helpful comments and suggestions. The views expressed herein are those of the authors and not necessarily those of the Federal Reserve Bank of Chicago, the Federal Reserve System, or the National Bureau of Economic Research.

NBER working papers are circulated for discussion and comment purposes. They have not been peerreviewed or been subject to the review by the NBER Board of Directors that accompanies official NBER publications.

(C) 2014 by Enrique G. Mendoza, Linda L. Tesar, and Jing Zhang. All rights reserved. Short sections of text, not to exceed two paragraphs, may be quoted without explicit permission provided that full credit, including $\odot$ notice, is given to the source. 
Saving Europe?: The Unpleasant Arithmetic of Fiscal Austerity in Integrated Economies Enrique G. Mendoza, Linda L. Tesar, and Jing Zhang

NBER Working Paper No. 20200

June 2014

JEL No. E6,E62,F34,F42,H6

\begin{abstract}
$\underline{\text { ABSTRACT }}$
What are the macroeconomic effects of tax adjustments in response to large public debt shocks in highly integrated economies? The answer from standard closed-economy models is deceptive, because they underestimate the elasticity of capital tax revenues and ignore cross-country spillovers of tax changes. Instead, we examine this issue using a two-country model that matches the observed elasticity of the capital tax base by introducing endogenous capacity utilization and a partial depreciation allowance. Tax hikes have adverse effects on macro aggregates and welfare, and trigger strong crosscountry externalities. Quantitative analysis calibrated to European data shows that unilateral capital tax increases cannot restore fiscal solvency, because the dynamic Laffer curve peaks below the required revenue increase. Unilateral labor tax hikes can do it, but have negative output and welfare effects at home and raise welfare and output abroad. Large spillovers also imply that unilateral capital tax hikes are much less costly under autarky than under free trade. Allowing for one-shot Nash tax competition, the model predicts a "race to the bottom" in capital taxes and higher labor taxes. The cooperative equilibrium is preferable, but capital (labor) taxes are still lower (higher) than initially. Moreover, autarky can produce higher welfare than both Nash and Cooperative equilibria.
\end{abstract}

Enrique G. Mendoza

Department of Economics

University of Pennsylvania

3718 Locust Walk

Philadelphia, PA 19104

and NBER

egme@sas.upenn.edu

Linda L. Tesar

Department of Economics

University of Michigan

Ann Arbor, MI 48109-1220

and NBER

ltesar@umich.edu
Jing Zhang

Research Department

Federal Reserve Bank of Chicago

230 S LaSalle Street

Chicago, IL 60604

jzhangzn@gmail.com 


\section{Introduction}

The world's advanced economies face a severe public debt crisis. Even before the onset of the Great Recession in 2008, countries in the eurozone exceeded the public debt ceiling of 60 percent of GDP, a condition set by the Maastricht Treaty. The slowing of economic activity combined with increased transfer payments, financial system bailouts, and fiscal stimulus programs resulted in a ballooning of public debt, as illustrated in Figure 1. In the countries at the center of the European debt crisis (Greece, Ireland, Italy, Spain, and Portugal, or GIIPS) gross public debt as a share of GDP rose 30 percentage points between 2008-2011, to a staggering 105 percent of GDP by 2011. The ten largest remaining eurozone members (EU10) also experienced large debt increases, albeit not as large as in the GIIPS. Their debt levels increased by nearly 18 percentage points of GDP, reaching a ratio of 0.79 in 2011, well in excess of the Maastricht condition. Debt ratios of this magnitude and on such a global scale are rare, and over the previous century occurred in times of major wars and during the Great Depression 1

The European debt crisis changed the nature of fiscal policy discussions in Europe. Until recently, the dominant issue in tax policy discussions was the harmonization of national tax rates and measures to limit tax competition (Sorensen, 2001, Kellerman and Kammer, 2009) 2. Once the debt crisis started, however, the focus shifted toward the implementation of country-specific fiscal austerity programs to address fiscal imbalances and bring the debt under control. A number of countries, including Portugal, Greece, Italy, Ireland and Spain, and to a lesser extent France and the Netherlands, adopted austerity packages that feature both expenditure cuts and increases in tax rates.

While much ink has been spilled in both the financial and academic press on the pros and cons of austerity measures in response to the debt crisis, there has been surprisingly little discussion of

\footnotetext{
${ }^{1}$ Japan, the United Kingdom and the United States have also seen their debts reach very high levels. Over the entire history of public debt in the United States, the data constructed by Bohn (2007) show that the surge in U.S. public debt during the Great Recession ranks below only the two World Wars, and is above the Civil War and the Great Depression.

${ }^{2}$ Since the 1970s, EU member states have worked to bring value-added taxes into alignment, to remove barriers to capital and labor movements across borders and to form a common European trade policy. The European Commission initiated steps to create a common playing field for corporate taxation (the Common Consolidated Corporate Tax Base), though the policy has not yet been adopted by eurozone Member States.
} 
the constraints imposed on fiscal policy by the fact the eurozone countries are highly integrated. Estimates of the sustainability of public debt (Abiad and Ostry, 2005, Mendoza and Ostry, 2008), fiscal space (Ostry, Ghosh, Habermeier, Chamon et al., 2010), and the scope for raising revenue (Trabandt and Uhlig, 2009, 2012) tend to treat countries as isolated economic units, setting aside the potential for significant erosion of tax bases across countries due to factor mobility, or for spillover effects on the budgets and welfare of other member countries $3^{3}$ Taking these effects into consideration is critical because the implications of fiscal austerity for macroeconomic aggregates and social welfare depend both on the particular fiscal policy that countries decide to follow as well as on the degree of integration of capital and goods markets.

This paper develops an open-economy macroeconomic framework for studying the international dimensions of fiscal adjustment and uses it to examine the positive and normative effects of tax policies targeted to offset shocks to public debt 4 The model captures the classic dynamic efficiency (or supply-side) effects of distortionary taxes on factor incomes and consumption, as well as the international externalities of domestic tax adjustments that result from cross-country mobility of goods and assets.

Our framework for analysis is similar to the Neoclassical model used in Mendoza and Tesar (1998, 2005) to study the international implications of domestic tax reforms that produce dynamic efficiency gains, and the setting proposed by Auray, Eyquem, and Gomme (2013) to study tax policies in open economies. An important limitation of these studies, and of those based on a wider class of quantitative Neoclassical and NeoKeynesian dynamic general equilibrium models used to study tax policy, is that the capital tax revenue has a very low elasticity to changes in tax rates, which runs contrary to empirical evidence (see Gruber and Rauh, 2007; Dwenger and Steiner, 2012). As a result, these models tend to overestimate the ability of the government to raise tax revenue in response to debt shocks.

\footnotetext{
${ }^{3}$ Externalities of fiscal policy have been widely discussed in the theoretical literature on international tax competition, much of which has focused on the EU, and in broader EU policy studies on tax harmonization and capital income tax competition (see, for example, the survey by Persson and Tabellini (1995), the books by Frenkel, Razin, and Sadka (1991) and Turnovsky (1997), and the quantitative studies by Klein, Quadrini, and Rios-Rull (2005), Sorensen (1999), Sorensen (2003) and Eggert (2000)).

${ }^{4}$ In this paper we limit the analysis to changes in tax rates, leaving the analysis of adjustments in expenditure policy to future work.
} 
To address this limitation, we introduce endogenous capital utilization and a limited tax allowance for capital depreciation 5 The two mechanisms interact in an important way. First, endogenous utilization allows agents to make short-run adjustments in the use of installed capital, and hence capital income, in response to capital tax changes. This weakens the capacity to raise tax revenue from capital taxes but also makes capital taxes less distorting. Second, the limited depreciation allowance widens the base of the capital tax, and makes capital taxes more distorting by increasing the marginal cost of capital utilization 6 The two mechanisms together result in a dynamic Laffer curve (i.e. a mapping of the present value of the primary fiscal balance as a function of tax rates) with a standard bell shape and a realistic elasticity of capital tax revenue. In contrast, without these mechanisms the dynamic Laffer curve for capital taxes is monotonically increasing for a wide range of tax rates.

In the model, national tax policies induce cross-country externalities that are driven by three transmission channels: (1) relative prices, because national tax changes alter the prices of financial assets (including internationally traded assets and public debt instruments) as well as factor prices at home and abroad; (2) the world distribution of wealth, because efficiency effects of national tax changes affect the allocations of capital and net foreign assets across countries; and (3) the erosion of tax revenues, because via the first two channels national tax policies affect the ability of foreign governments to raise tax revenue.

We conduct a quantitative analysis calibrated to eurozone data to study the positive and normative effects of alternative tax strategies that countries could follow to restore fiscal solvency in response to debt shocks. We feed the debt shocks observed in the eurozone since 2008 into the model and compute the short- and long-run effects on equilibrium allocations, prices and welfare that result from responding to those shocks with capital or labor taxes, assuming first that tax changes are undertaken unilaterally and then allowing for strategic interaction. The quantitative results produce important insights into the potential effects of fiscal austerity options facing Europe.

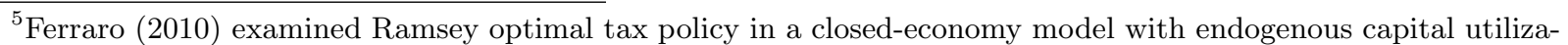
tion and an optimal choice of the depreciation allowance. He found that setting the capital income tax rate and the depreciation allowance equal is optimal.

${ }^{6}$ In representative-agent models calibrated to macroeconomic aggregates, setting the allowance to less than 100 percent of depreciation is also consistent with the data, since the allowance can only be claimed on nonresidential capital and mainly by businesses, rather than individuals.
} 
The first step in the analysis of unilateral tax adjustments is to construct dynamic Laffer curves in an experiment calibrated to an average European country. To plot these curves, the present discounted value of the primary fiscal balance is computed with the sequences of equilibrium allocations and prices obtained for a set of tax rates. Since we keep government outlays constant, these curves inherit the standard bell shape of the Laffer curves of tax revenues for distortionary taxes. Tax adjustment can restore fiscal solvency after the debt shock only if there is a tax rate that can produce an increase in the present discounted value of the primary fiscal balance of the same magnitude as the debt shock 7 This is done under relatively conservative assumptions, because the model assumes that there is no adverse impact of tax increases on long-run growth, and that debt is priced at a risk-free rate (i.e. there is no default risk).

Even under these highly favorable conditions, the model predicts that tax adjustments to restore fiscal solvency in response to the observed debt shocks may not be feasible, have large negative welfare effects, and yield large cross-country spillovers. These spillovers generate open-economy dynamic Laffer curves that are shifted down and to the left of the closed-economy curves, and also below closed-economy estimates of steady-state Laffer curves (e.g. Trabandt and Uhlig, 2010). For capital tax rates, the shift is so large that its maximum lies below what is needed to restore fiscal solvency after the debt shock. In contrast, labor tax hikes can restore fiscal solvency, but with negative effects on home allocations and welfare, and improvements abroad.

The large spillovers obtained with the unilateral tax adjustments indicate that strategic incentives are strong. This leads us to examine Nash solutions to one-shot tax competition games in which both regions adjust taxes strategically to offset their observed debt shocks. We first solve a baseline scenario with symmetric countries (i.e. a common debt shock set to 22 percentage points of GDP). The Nash game produces a race to the bottom in capital taxes from 0.20 to 0.09. Labor taxes increase from 0.35 to 0.43 . Welfare, using the standard measure of lifetime compensating variations in consumption, declines relative to the pre-crisis equilibrium by 1.66 percent. Moreover, in the absence of a cooperative solution or a redistribution of the debt burden (i.e. debt haircuts), each country attains higher welfare by moving to autarky.

\footnotetext{
${ }^{7}$ Hence, to conduct these experiments we solve for the equilibrium transitional dynamics and new steady state that result from a given set of tax changes, and calculate the equilibrium present discounted value of primary balances.
} 
When the model is calibrated to reflect the asymmetries between GIIPS and the EU10, three key findings emerge. First, Nash competition induces both regions to lower capital income taxes and to significantly raise labor taxes relative to pre-crisis rates. Welfare declines by 1.5 percent in GIIPS and by 1.1 percent in the EU10. Second, cooperation mitigates the cost of fiscal adjustment, but the losses remain sizable. Third, GIIPS prefers the autarky outcome, in which international externalities do not play a role, to even the most favorable cooperative allocation that allocates to it all of the benefits of coordination. This finding suggests that efforts to maintain trade and financial integration in Europe must take into account the negative externalities working through international markets as the countries adjust to the debt crisis.

The rest of the paper is organized as follows. Section 2 describes the model, examines the optimality conditions of households and firms, and defines the competitive equilibrium. Section 3 calibrates the model to eurozone data from before the 2008 crisis. Section 4 discusses the results of the quantitative analysis, starting with the implications of unilateral tax adjustments and the construction of dynamic Laffer curves, followed by the analysis of the solutions to Nash and Cooperative tax competition games. Section 5 provides conclusions.

\section{A Two-Country Model with Cross-Country Tax Externalities}

We study the fiscal adjustment in response to debt shocks using a two-country dynamic general equilibrium model. The model shares several of the features of the widely used two-country Neoclassical model with exogenous long-run balanced growth, except for two important differences: endogenous capacity utilization of the installed capital stock, and a limited tax allowance for capital depreciation expenses. The model abstracts from stochastic elements, because the focus of the analysis is on the transitional dynamics and long-run implications of fiscal adjustment, rather than on business cycle effects.

The world consists of two countries or regions: home $(H)$ and foreign $(F)$. The countries are perfectly integrated in goods and asset markets. The latter are modeled as one-period discount bonds, without loss of generality given the absence of uncertainty. Each country is inhabited by an infinitely-lived representative household. A representative firm in each country produces a single 
tradable good using capital and labor as inputs. Physical capital and labor are immobile factors, but trade in bonds is sufficient for inducing international spillovers of national tax policies, affecting the global distribution of wealth, the size of the global capital stock and its distribution across countries. In addition to this wealth reallocation mechanism, national tax policies also trigger global externalities via relative prices and fiscal revenue spillovers.

Following King, Plosser, and Rebelo (1988), growth is driven by labor-augmenting technological change that occurs at an exogenous rate $\gamma$. Accordingly, all variables (except labor and leisure) are rendered stationary by dividing by the level of this technological factor 8 In addition, the stationarity-inducing transformation of the model requires discounting utility flows at the rate $\tilde{\beta}=\beta(1+\gamma)^{1-\sigma}$, where $\beta$ is the standard subjective discount factor of time-separable preferences, and adjusting the laws of motion of physical and financial assets so that date- $t+1$ stocks grow by the balanced-growth factor $1+\gamma$.

We present below the structure of preferences, technology and the government sector of the home country. The same structure applies to the foreign country, and when relevant we distinguish variables across the two countries using asterisks to identify the foreign country.

\subsection{Households}

The representative home-country household has standard preferences:

$$
\sum_{t=0}^{\infty} \tilde{\beta}^{t} \frac{\left(c_{t}\left(1-l_{t}\right)^{a}\right)^{1-\sigma}}{1-\sigma}, \sigma>1, a>0, \text { and } 0<\tilde{\beta}<1
$$

The period utility function is the standard CRRA function in terms of a CES composite good made of consumption, $c_{t}$, and leisure. Since we assume a unit time endowment, leisure is defined as $1-l_{t}$, where $l_{t}$ is the supply of labor. $\frac{1}{\sigma}$ is the intertemporal elasticity of substitution in consumption, and $a$ governs the intertemporal elasticity of labor supply for a given value of $\sigma$.

The household takes as given government-determined proportional tax rates on consumption, labor income and capital income, denoted $\tau_{C}, \tau_{L}$, and $\tau_{K}$, respectively, and lump-sum government

\footnotetext{
${ }^{8}$ The assumption that growth is exogenous implies that tax policies do not affect long-run economic growth. This is in line with the empirical and quantitative findings of Mendoza, Milesi-Ferretti, and Asea (1997).
} 
transfer or entitlement payments, denoted by $e_{t}$. The household also takes as given the rental rates of labor $w_{t}$ and capital services $r_{t}$, and the prices of domestic government bonds and internationaltraded bonds, $q_{t}^{g}$ and $q_{t}$.

The household rents out capital and labor inputs to firms and makes the investment and capacity utilization decisions. Hence, the household rents to firms effective units of capital for production $\tilde{k}=m k$, where $k$ is the capital stock and $m$ the rate of utilization. We follow the standard practice from the literature on endogenous capacity utilization (e.g. Greenwood, Hercowitz, and Huffman, 1988) by modeling the cost of utilization as faster depreciation. The rate of depreciation of the capital stock increases with $m$, according to a convex function $\delta(m)=\chi_{0} m^{\chi_{1}} / \chi_{1}$, with $\chi_{1}>1$ and $\chi_{0}>0$ so that $0 \leq \delta(m) \leq 1$.

The price of capital and the price of consumer goods differ because investment incurs quadratic adjustment costs:

$$
\phi\left(k_{t+1}, k_{t}, m_{t}\right)=\frac{\eta}{2}\left(\frac{(1+\gamma) k_{t+1}-\left(1-\delta\left(m_{t}\right)\right) k_{t}}{k_{t}}-z\right)^{2} k_{t}
$$

where the coefficient $\eta$ determines the speed of adjustment of the capital stock, while $z$ is equal to the long-run investment-capital ratio so that at steady state the capital adjustment cost is zero 9

The household chooses intertemporal sequences of consumption, leisure, investment inclusive of adjustment costs $x$, international bonds $b$, domestic government bonds $d$, and utilization to maximize utility in (1) subject to a sequence of period budget constraints given by:

$$
\left(1+\tau_{c}\right) c_{t}+x_{t}+(1+\gamma)\left(q_{t} b_{t+1}+q_{t}^{g} d_{t+1}\right)=\left(1-\tau_{L}\right) w_{t} l_{t}+\left(1-\tau_{K}\right) r_{t} m_{t} k_{t}+\theta \tau_{K} \bar{\delta} k_{t}+b_{t}+d_{t}+e_{t},
$$

and the following law of motion for the capital stock:

$$
x_{t}=(1+\gamma) k_{t+1}-\left(1-\delta\left(m_{t}\right)\right) k_{t}+\phi\left(k_{t+1}, k_{t}, m_{t}\right),
$$

\footnotetext{
${ }^{9}$ It is well known that open-economy models with frictionless goods and asset markets require some form of capital adjustment costs in order to reduce the cyclical volatility of investment to observed levels, and to capture the fact that financial and physical assets cannot be adjusted at the same speed.
} 
for $t=0, \ldots, \infty$, given the initial conditions $k_{0}>0, b_{0}$, and $d_{0}$.

The left-hand-side of equation (3) measures household expenditures, which include purchases of consumption goods inclusive of the indirect tax, investment inclusive of capital adjustment costs, international bonds, and domestic government bonds. The right-hand side shows household aftertax income. This includes net-of-tax income from labor and effective capital services rented out to firms, a capital tax allowance for a fraction $\theta$ of depreciation costs, payments on holdings of public and international bonds, and lump-sum entitlement payments from the government, $e$.

The formulation of the depreciation allowance as $\theta \tau_{K} \bar{\delta} k_{t}$ in the above budget constraint is based on two assumptions about how the allowance is implemented in practice. First, depreciation allowances are usually set in terms of fixed depreciation rates of the declared value of capital, instead of the true physical depreciation rate that varies with utilization. To capture this fact, we assume that the depreciation rate for the capital tax allowance is set in terms of a constant depreciation rate $\bar{\delta}$. This differs from the actual physical depreciation rate $\delta(m)$. The second assumption is that, in this representative-agent model, the depreciation allowance only applies to a fraction $\theta$ of the capital stock. This reflects the fact that depreciation allowances generally apply to the capital income of businesses, not individuals, and also do not apply to residential capital ${ }^{10}$

Since the focus of the analysis is on studying the effects of tax adjustments to respond to debt shocks in countries with a high degree of openness, as is the case in the European Union, we assume that the two regions in the model have perfectly integrated goods and asset markets. The latter implies that international bond payments are not taxed. Also in line with other features of tax systems in industrial countries, including European countries, capital income is taxed according to the residence principle, but countries are allowed to tax capital income at different tax rates. These assumptions also imply that we must assume that physical capital is owned entirely by domestic residents, in order to support a competitive equilibrium with different capital taxes (see

\footnotetext{
${ }^{10}$ The standard assumption of a 100 percent depreciation allowance has two unrealistic implications. First, it renders $m$ independent of the capital income tax in the long run. Second, in the short run the capital tax affects the utilization decision margin only to the extent that it reduces the marginal benefit of utilization when traded off against the marginal cost due to changes in the marginal cost of investment. Alternatively, we could assume that there is a full depreciation allowance but that there are costs other than depreciation associated with capital utilization for which there is no tax allowance. These two formulations are isomorphic, but we opted for the partial depreciation allowance to maintain the traditional setup of capacity utilization.
} 
Mendoza and Tesar, 1998; Frenkel, Razin, and Sadka, 1991). Without this assumption, crosscountry arbitrage of returns across capital and bonds at common world prices implies equalization of pre- and post-tax returns on capital, which therefore requires identical capital income taxes across countries. Other forms of financial-market segmentation, such as trading costs or shortselling constraints, could be introduced for the same purpose, but would make the model less tractable 11

We impose a standard no-Ponzi-game condition on households. This restriction, along with the budget constraint in (2), implies that the present value of total household expenditures equals the present value of after-tax income plus initial asset holdings.

\section{$2.2 \quad$ Firms}

Since the household makes the investment and capital utilization decisions, and rents out to firms

effective capital services $\tilde{k}$, the representative firm's problem reduces to a static optimization problem. Firms hire labor and effective capital services to maximize profits, given by $y_{t}-w_{t} l_{t}-r_{t} \tilde{k}_{t}$, taking factor rental rates as given. The production function is assumed to be Cobb-Douglas:

$$
y_{t}=F\left(\tilde{k}_{t}, l_{t}\right)=\tilde{k}_{t}^{1-\alpha} l_{t}^{\alpha}
$$

where $\alpha$ is labor's share of income and $0<\alpha<1$. Firms behave competitively and thus choose $\tilde{k}_{t}$ and $l_{t}$ so as to equate their marginal products with their corresponding rental rates:

$$
\begin{aligned}
(1-\alpha) \tilde{k}_{t}^{-\alpha} l_{t}^{\alpha} & =r_{t} \\
\alpha \tilde{k}_{t} l_{t}^{\alpha-1} & =w_{t}
\end{aligned}
$$

Because of the linear homogeneity of the production technology, these factor demand conditions imply the standard result that the value of output equals total factor payments: $y_{t}=w_{t} l_{t}+r_{t} \tilde{k}_{t}$.

\footnotetext{
${ }^{11}$ The assumptions of immobile capital and residence-based taxation could be replaced with source-based taxation and this would result in similar saving and investment optimality conditions that would support competitive equilibria with different capital income tax rates across countries. While actual tax codes tend to be source-based, however, most industrial countries have bilateral tax treaties that render tax systems largely residence-based (see Frenkel, Razin, and Sadka, 1991).
} 


\subsection{Public Sector}

Fiscal policy in this economy has three components. The first component is government outlays, and is composed of pre-determined sequences of government purchases on goods and services, $g_{t}$, and transfer/entitlement payments to households, $e_{t}$, for $t=0, \ldots, \infty$. Government purchases are unproductive in the sense that they do not enter in household utility or the production function. Under this assumption, it would follow trivially that the optimal response to a debt shock should include setting $g_{t}=0$. We rule out this possibility because it is unrealistic, and also because if the model is modified to allow government purchases to provide utility or production benefits, cuts in these purchases would be distortionary in a way analogous to the taxes we are considering. Hence, in the quantitative experiments we assume that $g_{t}=\bar{g}$, where $\bar{g}$ is the steady state level of government purchases that prevailed before the debt shocks. Entitlement payments are treated in the same way (with $\bar{e}$ denoting the steady state level of entitlements before the debt shocks). Note, however, that since entitlements represent a form of lump-sum transfer payments, they are always non-distortionary in this representative agent setup. Still, they do impose on the government the need to raise distorting tax revenue, since we do not allow for lump sum taxation, and hence again the (trivial) optimal policy of eliminating transfer payments in response to debt shocks is ruled out.

The second component of fiscal policy is the tax structure. This includes the set of time invariant tax rates on consumption $\tau_{C}$, labor income $\tau_{L}$, capital income $\tau_{K}$, and the depreciation allowance limited to a fraction $\theta$ of depreciation expenses.

The third component is government debt, $d_{t}$. We assume the government is committed to repay its debt, and thus it must satisfy the following sequence of budget constraints for $t=0, \ldots, \infty$ :

$$
d_{t}-(1+\gamma) q_{t}^{g} d_{t+1}=\tau_{C} c_{t}+\tau_{L} w_{t} l_{t}+\tau_{K}\left(r_{t} m_{t}-\theta \bar{\delta}\right) k_{t}-\left(g_{t}+e_{t}\right)
$$

The right-hand-side of this equation shows the primary fiscal balance (tax revenues net of total government outlays). This primary balance is financed with the change in debt including debt service in the left-hand-side of the constraint.

Since the government is committed to repay, public debt dynamics must satisfy a standard 
no-Ponzi-game condition. This condition ensures that the present value of government revenues net of expenditures equals the initial public debt $d_{0} 12$ This is not an innocuous assumption in the analysis of fiscal adjustment in response to debt shocks, because it implies both that governments are committed to repay and that sovereign debt markets are working smoothly at all times. The findings of this paper show that even under these ideal conditions, there are large inefficiencies, welfare effects, and cross-country externalities involved in tax adjustments to respond to debt shocks.

Because we calibrate the model using fiscal data in shares of GDP, it is useful to write the intertemporal government budget constrain also in shares of GDP. Defining the primary balance as $p b_{t} \equiv \tau_{C} c_{t}+\tau_{L} w_{t} l_{t}+\tau_{K}\left(r_{t} m_{t}-\theta \bar{\delta}\right) k_{t}-\left(g_{t}+e_{t}\right)$, the constraint in shares of GDP is:

$$
\frac{d_{0}}{y_{0}}=\frac{p b_{0}}{y_{0}}+\sum_{t=1}^{\infty}\left(\left[\prod_{i=0}^{t-1} v_{i}\right] \frac{p b_{t}}{y_{t}}\right)
$$

where $v_{i} \equiv(1+\gamma) \psi_{i} q_{i}^{g}$ and $\psi_{i} \equiv y_{i+1} / y_{i}$. In this expression, the stream of future primary balances is discounted to account for long-run growth at rate $\gamma$, transitional growth $\psi_{i}$ as the economy converges to the long-run, and the equilibrium price of public debt $q_{i}^{g}$. Since $y_{0}$ is endogenous (i.e. it responds to debt shocks and required tax adjustments), it is useful to rewrite the above solvency condition so that the debt ratio in the left-hand-side is an exogenous initial condition. Multiplying both sides of the above condition times $\psi_{0}=\left(y_{0} / y_{-1}\right)$ we obtain:

$$
\frac{d_{0}}{y_{-1}}=\psi_{0}\left[\frac{p b_{0}}{y_{0}}+\sum_{t=1}^{\infty}\left(\left[\prod_{i=0}^{t-1} v_{i}\right] \frac{p b_{t}}{y_{t}}\right)\right] .
$$

The exogenous debt shocks that are the focus of our quantitative analysis are defined as observed changes in $d_{0} / y_{-1}$ (the debt ratio at the end of $t-1$, since $d_{0}$ is chosen on that date). Hence, the solvency condition (10) represents a constraint that the new regimes with altered tax policy in

\footnotetext{
${ }^{12}$ Note that, as explained in Mendoza and Tesar (1998), public debt in this model is Ricardian in the sense that the equilibrium dynamics of government debt can be equivalently characterized as a sequence of lump-sum transfers between government and households (separate from the "explicit" entitlement payments $e_{t}$ ), with these transfers set equal to the primary fiscal balance. We use this to simplify the numerical solution of the model. Once we have the equilibrium sequence of debt-equivalent transfers, the implied equilibrium dynamics for public debt follows from an initial condition calibrated to actual debt data and the government budget constraint.
} 
response to a debt shock must satisfy ${ }^{13}$ The left-hand-side is an exogenous constant taken from the data, and the right-hand-side is the present discounted value of the primary balance-GDP ratios (where $p b_{t}, y_{t}$ and $v_{t}$ are equilibrium outcomes), discounted taking into account exogenous long-run growth, endogenous transitional growth, and endogenous debt prices.

Combining the government's budget constraint with the household's budget constraint and the firm's zero-profit condition, we obtain the economy-wide resource constraint for the home region:

$$
F\left(m_{t} k_{t}, l_{t}\right)-c_{t}-g_{t}-x_{t}=(1+\gamma) q_{t} b_{t+1}-b_{t}
$$

\subsection{Competitive Equilibrium}

A competitive equilibrium for this two-region economy is a sequence of prices $\left\{r_{t}, r_{t}^{*}, q_{t}, q_{t}^{g}, q_{t}^{g *}, w_{t}\right.$, $\left.w_{t}^{*}\right\}$ and allocations $\left\{k_{t+1}, k_{t+1}^{*}, m_{t+1}, m_{t+1}^{*}, b_{t+1}, b_{t+1}^{*}, x_{t}, x_{t}^{*}, l_{t}, l_{t}^{*}, c_{t}, c_{t}^{*}, d_{t+1}, d_{t+1}^{*}\right\}$ for $t=0, \ldots, \infty$ such that: (a) households in each region maximize utility subject to their corresponding budget constraints and no-Ponzi game constraints, taking as given all fiscal policy variables as well as pre-tax prices and factor rental rates, (b) firms maximize profits subject to the Cobb-Douglas technology taking as given pre-tax factor rental rates, (c) the government budget constraints hold for given tax rates and exogenous sequences of government purchases and entitlements, and (d) the following market-clearing conditions hold in the global markets of goods and bonds:

$$
\begin{gathered}
\omega\left(y_{t}-c_{t}-x_{t}-g_{t}\right)+(1-\omega)\left(y_{t}^{*}-c_{t}^{*}-x_{t}^{*}-g_{t}^{*}\right)=0, \\
\omega b_{t}+(1-\omega) b_{t}^{*}=0
\end{gathered}
$$

where $\omega$ denotes the relative size of the two regions. This parameter will be calibrated to match the relative output shares of the two regions before the debt shocks occur.

\footnotetext{
${ }^{13}$ In detrended levels (which are ratios relative to the state of labor augmenting technology), we would have $d_{0}=p b_{0}+\sum_{t=1}^{\infty}\left(\left[\prod_{i=1}^{t} q_{i}^{s}\right](1+\gamma)^{t} p b_{t}\right)$.
} 


\subsection{Optimality Conditions, Tax Distortions and International Externalities}

The optimality conditions of the household and firm problems provide useful intuition for characterizing the model's tax distortions and their international externalities. Consider first the Euler equations for capital (excluding adjustment costs for simplicity), international bonds and domestic government bonds. These conditions imply that the following arbitrage conditions hold:

$$
\begin{aligned}
& \frac{(1+\gamma) u_{1}\left(c_{t}, 1-l_{t}\right)}{\tilde{\beta} u_{1}\left(c_{t+1}, 1-l_{t+1}\right)}=\left(1-\tau_{K}\right) F_{1}\left(m_{t+1} k_{t+1}, l_{t+1}\right) m_{t+1}+1-\delta\left(m_{t+1}\right)+\tau_{K} \theta \bar{\delta}=\frac{1}{q_{t}}=\frac{1}{q_{t}^{g}}, \\
& \frac{(1+\gamma) u_{1}\left(c_{t}^{*}, 1-l_{t}^{*}\right)}{\tilde{\beta} u_{1}\left(c_{t+1}^{*}, 1-l_{t+1}^{*}\right)}=\left(1-\tau_{K}^{*}\right) F_{1}\left(m_{t+1}^{*} k_{t+1}^{*}, l_{t+1}^{*}\right) m_{t+1}^{*}+1-\delta\left(m_{t+1}^{*}\right)+\tau_{K}^{*} \theta \bar{\delta}=\frac{1}{q_{t}}=\frac{1}{q_{t}^{g *}} .
\end{aligned}
$$

The assumption that the regions are fully integrated in financial markets implies that the households' intertemporal marginal rates of substitution in consumption are equalized across regions, and are also equal to the rate of return on international bonds. Since physical capital is not mobile and capital income taxes are residence based, households in each region face their own region's distortionary tax on capital income. As a result, arbitrage equalizes the after-tax returns on capital across regions, but pre-tax returns differ. Hence, the capital stock and output differ across regions due to differences in capital taxation. Arbitrage in asset markets also implies that the price of external bonds and domestic public bonds are equalized. Hence, at equilibrium: $q_{t}=q_{t}^{g}=q_{t}^{g *}$.

As shown in Mendoza and Tesar (1995), unilateral changes in the capital income tax result in a permanent reallocation of physical capital, and ultimately a permanent shift in wealth, from the high-tax to the low-tax region. Thus, even though physical capital is not mobile across countries directly, perfect mobility of financial capital and arbitrage of asset returns induces international mobility of physical capital. In the stationary state with balanced growth, however, the global interest rate $R$ (the inverse of the bond price, $R \equiv 1 / q$ ) is a function of $\beta, \gamma$ and $\sigma$ :

$$
R=\frac{(1+\gamma)^{\sigma}}{\beta}
$$

and thus is independent of tax rates. The interest rate does change along the transition path and alters the paths of consumption, output and international asset holdings. In particular, in the tax 
competition games we study later, each country has an incentive to behave strategically by tilting the path of the world interest rate in its favor to attract more capital. When both countries attempt such a strategy, the outcome is lower capital taxes but also lower welfare for both (which is the standard race-to-the-bottom result of the tax competition literature).

Consider next the optimality condition for labor supply. This condition reflects the standard distortionary effects of labor and consumption taxes:

$$
\frac{u_{2}\left(c_{t}, 1-l_{t}\right)}{u_{1}\left(c_{t}, 1-l_{t}\right)}=\frac{1-\tau_{L}}{1+\tau_{C}} F_{2}\left(k_{t}, l_{t}\right)
$$

Taxes on labor and consumption together drive a wedge $\left(1-\tau_{W}\right) \equiv\left(1-\tau_{L}\right) /\left(1+\tau_{C}\right)$ between the leisure-consumption marginal rate of substitution and the pre-tax real wage (which is equal to the marginal product of labor). Since government purchases are kept constant and the consumption tax is constant over time and known with certainty, consumption taxation does not distort saving plans, and hence labor and consumption taxes are equivalent: Any $\left(\tau_{C}, \tau_{L}\right)$ pair consistent with the same $\tau_{W}$ yields identical allocations, prices and welfare. Since European consumption tax harmonization agreements limit the scope of national adjustments in consumption taxes, however, we assume that any adjustments to $\tau_{W}$ implemented to respond to a debt shock reflect changes in $\tau_{L}$, with $\tau_{C}$ constant at its pre-debt-shock rate.

The distortions of capital, labor and consumption taxes discussed in the previous paragraphs are standard in a wide class of Neoclassical and New Keynesian DSGE models. These models, however, generally underestimate the elasticities of both investment and capital income tax revenues to changes in capital taxes, because the capital stock is pre-determined at the beginning of each period, and changes gradually as it converges to its balanced-growth steady state. In contrast, in this model the government's ability to tax capital income is significantly hampered because capital income taxes not only drive a wedge between intertemporal marginal rates of substitution in consumption and rates of return on capital, they also distort capacity utilization decisions. In particular, the optimal choice for capacity utilization implies:

$$
F_{1}\left(m_{t} k_{t}, l_{t}\right)=\frac{1+\Phi_{t}}{1-\tau_{K}} \delta^{\prime}\left(m_{t}\right),
$$


where $\Phi_{t}=\eta\left(\frac{(1+\gamma) k_{t+1}-\left(1-\delta\left(m_{t}\right)\right) k_{t}}{k_{t}}-z\right)$ is the marginal adjustment cost of investment. The capital tax creates a wedge between the marginal benefit of utilization on the left-hand-side of this condition, which is the after-tax marginal product of effective capital already installed, and the marginal cost of utilization on the right-hand-side, which is the marginal change in the rate of depreciation caused by changes in utilization.

It follows from the above expression that an increase in $\tau_{k}$, everything else constant, reduces the utilization rate. This follows from the concavity of the production function and the fact that $\delta\left(m_{t}\right)$ is increasing and convex. Intuitively, a higher capital tax reduces the after-tax marginal benefit of utilization, and thus reduces the rate of utilization. Note also that the magnitude of this distortion depends on whether the capital stock is above, below or at its balanced-growth steady state. This is because the sign of $\Phi_{t}$ depends on Tobin's Q, which is given by $Q_{t}=1+\Phi_{t}$. If $Q_{t}$ is greater than $1\left(\Phi_{t}>0\right)$, the desired investment rate is higher than the steady-state investment rate. In this case, $Q_{t}>1$ increases the marginal cost of utilization (because higher utilization means faster depreciation, which makes it harder to attain the higher target capital stock). The opposite happens when $\mathrm{Q}$ is less than $1\left(\Phi_{t}<0\right)$. In this case, the faster depreciation at higher utilization rates makes it easier to run down the capital stock to reach its lower target level. Thus, an increase in $\tau_{k}$ induces a larger decline in the utilization rate when the desired investment rate is higher than its long-run target (i.e. $\Phi_{t}>0$ ).

The interaction of endogenous utilization and the limited depreciation allowance plays an important role in our analysis. Endogenous utilization means that the government cannot treat the existing (pre-determined) capital stock as an inelastic source of taxation at any given date, because effective capital services rented for production decline with the capital tax even when the capital stock is already installed. This weakens the revenue-generating capacity of capital taxation, but it also makes capital taxes less distorting, since it gives agent's an additional margin of adjustment in response to capital tax hikes. On the other hand, the limited depreciation allowance widens the base of the capital tax, but it also strengthens the distortionary effect of $\tau_{k}$ by reducing the post-tax marginal return on capital (see eq. 14). We will show in the quantitative section that the two mechanisms together result in a dynamic Laffer curve with the familiar bell shape and 
consistent with empirical estimates of the capital tax base elasticity, while removing them results in a Laffer curve that is nearly linearly increasing for a wide range of capital taxes.

The cross-country externalities that result from the tax distortions discussed in this subsection can be summarized as resulting from three distinct transmission channels. First, relative prices, because national tax changes alter the prices of financial assets (including internationally traded assets and public debt instruments) as well as the rental prices of effective capital units and labor

in both regions. Second, the distribution of wealth across the regions, because efficiency effects of tax changes by one region affect the allocations of capital and net foreign assets across regions (even when physical capital is not directly mobile). Third, the erosion of tax revenues, because via the first two channels the tax policies of one region affect the ability of the other region to raise tax revenue. When one region responds to a debt shock by altering its tax rates, it generates external effects that can harm or benefit the other region via these three channels.

\section{Calibration and Pre-Crisis Initial Conditions}

This section reviews macroeconomic data to characterize the pre-debt-crisis initial conditions and discusses the calibration of the model. We use data from the 15 largest countries in the eurozone (Cyprus and Malta are excluded). In the baseline calibration, we consider fully symmetric regions calibrated to eurozone-wide aggregates, and we also construct an asymmetric scenario in which we introduce region heterogeneity in the parameters in which it is empirically significant (public debt ratios, fiscal policy parameters, trade balances and relative economic size).

\subsection{Pre-crisis Initial Conditions in the eurozone}

Table 1 shows key statistics for aggregate expenditures and fiscal variables as shares of GDP for eleven eurozone countries. The last three columns show GDP-weighted averages for the GIIPS region (Greece, Ireland, Italy, Portugal and Spain), the EU10 region (the remaining countries), and the full 15-country sample, denoted "All EU." The All EU values will be used as targets for the baseline calibration, and the GIIPS and EU10 values will be used for the asymmetric calibration. The GIIPS GDP was about half the size of the EU10 GDP in 2008, so the GIIPS share is about 
one-third of the two regions' aggregate output.

The first three rows of Table 1 show estimates of effective tax rates on consumption, labor and capital calculated from revenue and national income accounts statistics using the methodology introduced by Mendoza, Razin, and Tesar (1994) (MRT). These tax rates have been widely used in a number of studies including Carey and Tchilinguirian (2000), Sorensen $(2001)$ and recently by Trabandt and Uhlig $(2009,2012)$. The MRT methodology uses the wedge between reported pre-tax and post-tax macro estimates of consumption, labor income and capital income to estimate the effective tax rate levied on each of the three tax bases. This methodology has two main advantages. First, it provides a fairly simple approach to estimating effective tax rates at the macro level using readily available data, despite the complexity of the various credits and deductions of national tax codes. Second, these tax rates correspond directly to the tax rates in a wide class of representativeagent models with taxes on consumption and factor incomes, including the model proposed here. The main drawback of the MRT tax rates is that they are average, not marginal, tax rates, but because they are intended for use in representative-agent models, this disadvantage is less severe than it would be in a model with heterogeneous agents. Moreover Mendoza, Razin, and Tesar (1994) show that existing estimates of aggregate marginal tax rates have a high time-series correlation with the MRT effective tax rates, and that both have similar cross-country rankings.

Following Trabandt and Uhlig (2009), we modify the MRT estimates of labor and capital taxes by adding supplemental wages (i.e. employers' contributions to social security and private pension plans) to the tax base for personal income taxes. These data were not available at the time of the MRT 1994 calculations and, because this adjustment affects the calculation of the personal income tax rate, which is an initial step for the calculation of labor and capital income tax rates, it alters the estimates of both. In general, this adjustment makes the labor tax base bigger and therefore the labor tax rate smaller than the MRT original estimates. 14

Table 1 shows that 2008 tax rates were not very different across EU10 and GIIPS. This reflects the tax harmonization treaties and directives adopted by the European Union since the 1960s, as

\footnotetext{
${ }^{14}$ Trabandt and Uhlig make a further adjustment to the MRT formulae by attributing some of the operating surplus of corporations and non-incorporated private enterprises to labor, with the argument that this represents a return to entrepreneurs rather than to capital. We do not make this modification because the data do not provide enough information to determine what fraction of the operating surplus should be allocated to labor.
} 
well as the effects of competition in corporate income taxation. Consumption and labor tax rates are slightly higher in EU10 than in GIIPS (0.18 v. 0.14 for consumption and $0.36 \mathrm{v}$. 0.33 for labor), and capital taxes are just a notch higher in GIIPS than in EU10 (0.21 v. 0.20) 15 This relative homogeneity of the pre-debt-crisis tax structures is worth noting, because it contrasts with the sizable difference in the size of the debt shocks across GIIPS and EU10 documented below. Hence, the quantitative experiments conducted in the next section using the asymmetric calibration focus on tax adjustments in response to heterogeneous public debt shocks across countries starting from relatively homogeneous tax systems.

With regard to aggregate expenditure ratios, the GIIPS region has higher consumption and investment shares of GDP than EU10 by 4 and 3 percentage points respectively. Their government expenditure shares (purchases of goods and services, excluding transfers) are about the same, at one-fifth of GDP. These three expenditure ratios are fairly stable over time, so using 2008 values or time-series averages for the calibration makes little difference. This is not true, however, for net exports, which show an average of -0.1 percent for GIIPS over the 1995-2011 period but by 2008 had dropped to -3 percent. In the asymmetric calibration we use this value, and since the model only has two regions, it imposes a 3 percent pre-crisis steady state trade surplus on the EU10. For the baseline symmetric calibration, the All EU trade balance was negligible in 2008, so we set it to zero in the pre-crisis steady state for simplicity. Examining the countries individually, GIIPS countries tend to have trade deficits with the exception of Ireland, and in EU10 Germany and the Netherlands have large trade surpluses that influence signficantly the GDP weighted average for EU10. Note, however, that these trade balances include all external trade of the eurozone countries, not just trade flows within the eurozone.

In terms of fiscal flows, Eurostat data on total tax revenues and government outlays (including both expenditures and transfer payments) show that both revenues and outlays are slightly higher in EU10 than GIIPS, by 3 and 2 percentage points respectively. The gap between revenues and expenditures, however, is about the same in both regions.

\footnotetext{
${ }^{15}$ In contrast, these tax structures differ sharply from those of non-European industrial countries (see Mendoza, Razin, and Tesar, 1994 Mendoza, Milesi-Ferretti, and Asea, 1997, for detailed international comparisons of tax systems across all OECD industrial countries).
} 
The bottom panel of Table 1 reports government debt to GDP ratios and their change between end-2007 (beginning of 2008) and end-2011. These changes are our estimate of the "debt shocks" that each country and region experienced, and hence they are the key exogenous impulse used in the quantitative experiments of the next Section. The debt ratios correspond to consolidated gross debt of the general government as reported by Eurostat, which is the measure used to evaluate compliance with the Maastricht Treaty. Under the Treaty, eurozone governments are to keep this ratio below 60 percent of GDP. As the table shows, however, debt ratios between end-2007 and 2011 rose sharply. Only five countries were in compliance with the Maastricht limit, and all of the large European economies in both EU10 and GIIPS had debt ratios significantly higher than 0.6. The debt shock in EU10 amounts to an increase of 18 percentage points of GDP (reaching a 79 percent debt ratio by 2011), while in GIIPS the ratio increased by 30 percentage points, reaching a

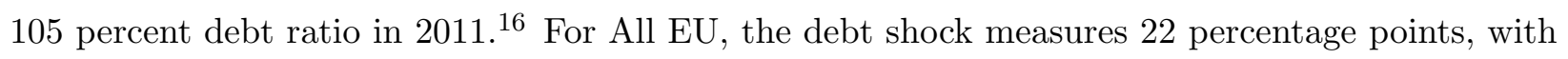
the debt ratio rising from 66 to 88 percent.

\subsection{Calibration}

Table 2 lists the parameter values of the model's baseline calibration, and the information from the All EU column of Table 1 or the existing literature that was used to target them. The calibration is designed to represent the balanced-growth steady state that prevailed before the debt shocks occurred, using 2008 observations from the data as empirical proxies for the corresponding allocations (as explained earlier, investment and consumption shares for 2008 or time-series averages since 1970 are not markedly different). The model is calibrated to a quarterly frequency, and the calibration strategy proceeds as described in the paragraphs below.

The fiscal policy parameters include the tax rates, the share of government expenditures in GDP, the public debt ratio and the limit on the depreciation allowance. The tax rates, government expenditures share and debt ratio are calibrated to the values in the All EU column of Table 1 . $\tau_{K}=0.2, \tau_{L}=0.35, \tau_{C}=0.16, g / y=0.21$ and $d / y=0.66$. These labor and consumption tax rates imply a consumption-leisure tax wedge of $\tau_{W}=0.44$. The limit on the depreciation

\footnotetext{
${ }^{16}$ GDP fell during this interval, which contributed to the increase in the debt to GDP ratio, but the decline in GDP is swamped by the large increase in debt, particularly in GIIPS.
} 
allowance, $\theta$, is set to capture the facts that tax allowances for depreciation costs apply only to capital income taxation levied on businesses, not individuals, and do not apply to residential capital (which is included in $k$ ). Hence, the value of $\theta$ is set as $\theta=\left(R E V_{K}^{\text {corp }} / R E V_{K}\right)\left(K^{N R} / K\right)$, where $\left(R E V_{K}^{\text {corp }} / R E V_{K}\right)$ is the ratio of revenue from corporate capital income taxes to total capital income tax revenue, and $\left(K^{N R} / K\right)$ is the ratio of non-residential fixed capital to total fixed capital. Using 2007 data from OECD Revenue Statistics for revenues, and from the European Union's EU KLEMS database for capital stocks for the six countries with enough data coverage (Austria, Finland, Germany, Italy, Netherlands and Spain), these ratios range from 0.39 to 0.48 for $\left(R E V_{K}^{\text {corp }} / R E V_{K}\right)$ and from 37 to 46 percent for $\left(K^{N R} / K\right)$. Weighting by GDP, the aggregate value of $\theta$ is 0.22 .

Consider next the technology parameters. The labor share of income, $\alpha$, is set to 0.61 , following Trabandt and Uhlig (2009). The quarterly rate of labor-augmenting technological change, $\gamma$, is 0.0022 , which corresponds to the 0.9 percent annual average growth rate in real GDP per capita observed in the Euro area between 2000 and 2011 based on Eurostat data. Since the countries are symmetric in the baseline calibration, relative country size is set to $\omega=0.50$.

To calibrate the depreciation rate function, we start by normalizing the long-run capacity utilization rate to $\bar{m}=1$. Given $\gamma=0.0022$ and the investment- and capital-output ratios from the data, we solve for the long-run depreciation rate from the steady-state law of motion of the capital stock $(x / y=(\gamma+\delta(\bar{m})) k / y)$. This yields $\delta(\bar{m})=0.0164$ per quarter ${ }^{17}$ The value of $\chi_{0}$ follows then from the optimality condition for utilization at steady state, using $\alpha=0.61$ and $k / y=2.97$, which yields $\chi_{0}=(1-\alpha) /(k / y)=0.03$. Given this, the value of $\chi_{1}$ follows from evaluating the depreciation rate function at steady state, which implies $\chi_{0} \bar{m}^{\chi_{1}} / \chi_{1}=0.0164$. Solving for $\chi_{1}$ yields $\chi_{1}=1.58$. The constant depreciation rate for claiming the depreciation tax allowance, $\bar{\delta}$, is set equal to the steady state depreciation rate. Hence, $\bar{\delta}=\delta(\bar{m})=0.0164$.

For preference parameters, we set $\sigma=2.0$ which is the value commonly used in the Macro literature. The exponent of leisure in utility, $a=2.675$ is from Mendoza and Tesar (1998). This value supports a labor allocation of 18.2 hours, which is in the range of the 1993-1996 averages of

\footnotetext{
${ }^{17}$ Investment rates are from the OECD National Income Accounts and capital-output ratios are from the AMECO database of the European Commission. The 2008 GDP-weighted average investment rate across the GIIPS and EU10 is $x / y=0.222$ (see also the last column of Table 1), and the 2007 average capital-output ratio is $k / y=2.97$ (which is also the average over the $2000-2008$ period).
} 
hours worked per person aged 15 to 64 in France (17.5), Germany (19.3) and Italy (16.5) reported by Prescott (2004).

The value of $\beta$ follows from the steady-state Euler equation for capital accumulation, using the values set above for the other parameters that appear in this equation:

$$
\frac{\gamma}{\tilde{\beta}}=1+\left(1-\tau_{K}\right)(1-\alpha) \frac{y}{k}-\delta(\bar{m})+\tau_{K} \theta \bar{\delta}
$$

This yields $\tilde{\beta}=0.992$, and then since $\tilde{\beta}=\beta(1+\gamma)^{1-\sigma}$ it follows that $\beta=0.9942$. The values of $\beta, \gamma$ and $\sigma$ pin down the steady-state gross real interest rate, $R=\beta^{-1}(1+\gamma)^{\sigma}=1.0102$. This is equivalent to a net annual real interest rate of about 4.2 percent.

Once the interest rate is determined, the economy's resource constraint pins down the steadystate ratio of net foreign assets to GDP. Since the data indicates $t b / y=0$ for the symmetric baseline, $b / y=(t b / y) /\left[(1+\gamma) R^{-1}-1\right]=0$. In addition, the steady-state government budget constraint can be used to solve for the implied ratio of government entitlement payments to GDP $e / y=R e v / y-g / y-(d / y)\left[1-(1+\gamma) R^{-1}\right]=0.163$.

Under this calibration approach, both $b / y$ and $e / y$ are necessarily obtained as residuals, given that the values of all the terms in the right-hand-side of the equations that determine them have already been set. Hence, they generally will not match their empirical counterparts. In particular, for entitlement payments the model underestimates significantly the 2008 observed ratio of entitlement payments to GDP (0.163 in the model v. 0.26 in the data for All EU). Notice, however, that when the model is used to evaluate tax policies to restore fiscal solvency in response to debt shocks, the fact that entitlement payments are lower than in the data strengthens our results. We find that restoring fiscal solvency implies non-trivial tax adjustments with sizable welfare costs and cross-country spillovers, all of which would be even larger with higher government revenue requirements due to higher entitlement payments.

The value of the investment-adjustment-cost parameter, $\eta$, cannot be set using steady-state conditions, because at steady state adjustment costs wash out from the model by construction. Hence, we set the value of this parameter so that the model is consistent with the mid-point of the empirical estimates of the short-run elasticity of the capital tax base to changes in capital tax rates. 
The range of empirical estimates is $0.1-0.5$, so the target midpoint is $0.3{ }^{18}$ Under the baseline symmetric calibration, the model matches this short-run elasticity when we set $\eta=2.0$. This value of $\eta$ is also in line with estimates in House and Shapiro (2008) of the response of investment in long-lived capital goods to relatively temporary changes in the cost of capital goods 19

An alternative calibration strategy would have been to set $\eta$ directly to the 1-2.5 range indicated by the estimates of House and Shapiro (2008), and calibrate $\chi_{1}$, the curvature parameter in the depreciation rate function, to match the capital tax base elasticity. This would require also a different approach to calibrate $\chi_{0}$ and $\bar{\delta}$. The value of $\chi_{0}$ would be pinned down by the fact that, given $\bar{m}=1$, the functional form of $\delta(m)$ implies $\chi_{0}=\chi_{1} \delta(\bar{m})$, and the value of $\bar{\delta}$ would then be solved for using the optimality condition for utilization evaluated at steady state. This calibration strategy is about equivalent quantitatively to the one we followed, however, because under our calibration strategy setting $\eta$ to match the capital tax base elasticity we obtained a value of $\eta$ well inside the House-Shapiro range of empirical estimates of this parameter.

Table 3 reports the 2008 GDP ratios of key macro-aggregates in the data and the model's balanced-growth, steady-state allocations for the baseline symmetric calibration and for the GIIPSEU10 asymmetric calibration. As noted earlier, the latter captures the observed differences in the size of the regions, in all their fiscal policy parameters and in their trade balances. The ratios of the model and the data in the symmetric baseline are nearly identical by design, because the ratios from the data were used as calibration targets (except the consumption-output ratio). The small differences in data and model columns for the GIIPS-EU10 scenario suggest that even in the asymmetric case the model does a good job at capturing the pre-debt-crisis conditions in these regions as the initial balanced-growth stationary state.

\footnotetext{
${ }^{18}$ Gruber and Rauh (2007) obtained a main estimate of 0.2 for the elasticity of the corporate tax base relative to corporate taxes in the United States, and Dwenger and Steiner (2012) obtained around 0.5 for Germany. Moreover, Grubler and Rauh also noted the following after surveying the much larger literature estimating the elasticity of individual tax bases to individual tax rates: "The broad consensus from this literature is that the elasticity of taxable income with respect to the tax rate is roughly 0.4. Moreover, the elasticity of actual income generation through labor supply/savings, as opposed to reported income, is much lower. And most of the response of taxable income to taxation appears to arise from higher income groups."

${ }^{19}$ They estimated the elasticity of substitution between capital and consumption goods to be in the range of 6 to 14. In models with the standard Hayashi setup of capital adjustment costs without utilization choice, this elasticity is equal to $1 /(\eta \delta)$. Hence, for the value of $\delta(\bar{m})=0.0164$ in our model, this would imply values of $\eta$ in the range between 1 and 2.5 .
} 


\section{Quantitative Analysis}

We now turn to quantitative experiments that illustrate the macroeconomic implications of changes in capital and labor tax rates that could be undertaken to restore fiscal solvency (i.e. balance the intertemporal government budget constraint) in response to shocks to the initial public debt ratio. As explained earlier, since labor and consumption taxes are equivalent and consumption taxes are unchanged at the pre-debt shock rates, adjustments in labor taxes correspond to adjustments in the consumption-leisure tax wedge $\left(\tau_{W}\right)$. We refer to the home region as $\mathrm{H}$ and the foreign region as F. We conduct two sets of experiments. In the first set, we assume that $\mathrm{H}$ implements unilateral increases in either capital or labor tax rates, and study the effects on equilibrium allocations and prices as well as social welfare in the $\mathrm{H}$ and $\mathrm{F}$ regions, and compare also with the effects obtained in similar experiments in which $\mathrm{H}$ implements tax adjustments as a closed economy. In light of the significant externalities obtained with unilateral tax changes, the second set of experiments examines tax adjustments that restore fiscal solvency as solutions of cooperative and non-cooperative tax competition games between $\mathrm{H}$ and $\mathrm{F}$.

The algorithms follow a first-order approximation approach to the model's equilibrium conditions around the balanced-growth stationary state 20 Since the model consists of two regions trading freely in goods and asset markets, however, standard perturbation methods widely used in the Macro literature cannot be applied directly. In particular, trade in bonds implies that, when the model's pre-debt-crisis steady state is perturbed by the debt shocks and the tax changes aimed at restoring fiscal solvency, the equilibrium transition paths of allocations and prices and the new steady-state equilibrium need to be solved for simultaneously. This is because in models of this class stationary equilibria depend on initial conditions and thus cannot be determined separately from the solution of the models' dynamics. For this reason, Mendoza and Tesar (1998) developed a solution method that nests a perturbation routine for solving transitional dynamics within a shooting algorithm. This method iterates on candidate values of the new long-run net foreign asset

\footnotetext{
${ }^{20}$ Mendoza and Tesar $(1998,2005)$ use a similar method. In their exercise, the algorithm solved for competitive equilibria and Nash and cooperative games in situations in which capital income taxes were removed and the present value of the revenue is replaced with other taxes. In this paper we solve for changes in capital and labor taxes that can restore fiscal solvency in response to changes in the initial public debt ratio.
} 
positions to which the model converges after being perturbed by debt and tax changes, until the candidate values match the positions the model converges to when simulated forward to its new steady state starting from the calibrated pre-debt-crisis initial conditions (see Mendoza and Tesar, 1998, for details).

\subsection{Unilateral Tax Increases and Dynamic Laffer Curves}

The first step in the quantitative analysis is to examine how unilateral movements in capital and labor taxes alter the borrowing ability of the government (i.e. increase the present value of the primary fiscal balance) in the symmetric baseline calibration. For this purpose, as mentioned earlier, we construct "Dynamic Laffer Curves" that map values of $\tau_{K}$ or $\tau_{L}$ into the present discounted value of the primary fiscal balance they support at equilibrium. For each value of the tax rates, the sequence of total tax revenue varies as equilibrium allocations and prices vary, while government purchases and entitlement payments are kept constant. In addition, the present value computation captures the effect of changes in the equilibrium sequence of interest rates, which reflect the government's borrowing costs. We express the result as a ratio of pre-debt-crisis output $y_{-1}$, so that it corresponds to the term in the right-hand-side of the intertemporal government budget constraint (10), and in graphs we plot the result as a change relative to the pre-debt-crisis public debt ratio. Hence, the values along the vertical axis of the dynamic Laffer curves show the change in the initial debt ratio that particular values of $\tau_{K}$ or $\tau_{L}$ can support at equilibrium ${ }^{21}$ These Laffer curves cross the zero line at the calibrated tax rates of the pre-debt-crisis stationary equilibrium by construction, and a given tax rate can restore fiscal solvency for a given debt shock only if at that tax rate the dynamic Laffer curve returns a value at least as large as the debt shock.

Since the $\mathrm{F}$ region is affected by spillovers of the unilateral tax changes in $\mathrm{H}$, there needs be an adjustment in $\mathrm{F}$ so that its intertemporal government budget constraint continues to hold at the same level (i.e. the same present discounted value of primary fiscal balances). For simplicity, we refer to this adjustment as maintaining "revenue neutrality" in the F region. This can be done by

\footnotetext{
${ }^{21}$ Since $g_{t}+e_{t}$ remains constant at the pre-crisis level and equilibrium interest rates display relatively small movements, these Laffer Curves display the same shape as standard dynamic Laffer curves that map taxes into the present value of tax revenue, instead of the primary fiscal balance.
} 
changing foreign transfers, taxes or government purchases. The difference is that, since government purchases are unproductive and taxes are distorting, reducing tax rates in response to favorable tax spillovers from the $\mathrm{H}$ region is more desirable than increasing transfer payments. Hence, since we are also assuming that government purchases remain constant in both regions, we allow $\mathrm{F}$ to maintain revenue neutrality by adjusting $\tau_{L}^{*}$.

\section{Dynamic Laffer Curves for Capital Taxes}

The solid line in Figure 2 shows the dynamic Laffer curve of the $\mathrm{H}$ region for changes in $\tau_{K}$, together with the corresponding curve assuming $\mathrm{H}$ is in autarky (the closed-economy dotted line). As explained above, at the pre-debt-crisis calibrated value of $\tau_{K}=0.2$, the Laffer curves intersects the zero line, because the present value of the primary balance does not change relative to the pre-debt-crisis equilibrium.

As shown in Table 1, the debt shock for the GDP-weighted average of the eurozone is equal to an increase of 0.22 in the debt ratio. This is indicated as the "Debt Shock" line in Figure 2. Hence, 0.22 is the amount by which the present value of the primary fiscal balance as share of GDP needs to increase to restore fiscal solvency in the baseline symmetric calibration. The Figure shows that there is no value of $\tau_{K}$ that can restore fiscal solvency in the $\mathrm{H}$ region in the open economy. The maximum point of the dyamic Laffer curve is attained with a tax rate of 0.31 , with an associated maximum value equal to an increase in the present value of the primary balance of 9 percentage points of GDP, far short of the required 22. The dynamic Laffer curve under autarky is steeper at the pre-debt-crisis tax rate, and it peaks at a higher tax rate of 40 percent, raising the present value of the primary balance by more than the required 22 . As it happens, the $\mathrm{H}$ region can restore fiscal solvency in autarky at almost the same tax rate corresponding to the maximum point of the open-economy Laffer curve.

The fact that $\mathrm{H}$ acting unilaterally can generate more revenue as it increases $\tau_{K}$ if the economy is closed than open shows that evaluating "fiscal space," or the capacity to raise revenue, without taking into account international trade in goods and assets and cross-country tax externalities, leads to substantial overestimation of the effectiveness of capital tax hikes as a tool to restore fiscal solvency. It also suggests that, by focusing on unilateral capital tax austerity alone, countries that 
have heavier outstanding debt burdens have non-trivial incentives to consider moving to autarky, imposing capital controls and/or trade barriers, or repudiating their debt.

Table 4 summarizes the effects that result from an unilateral increase in $\tau_{K}$ to the maximum point on the open-economy Laffer curve (31 percent). In this scenario, the implied adjustment in the labor tax in $\mathrm{F}$ to maintain revenue neutrality in response to the positive externalities from the capital tax hike in $H$, reduces $\tau_{L}^{*}$ from 0.35 to 0.33 . Since H's capital tax rate increases by 11 percentage points, and this tax is highly distorting, $\mathrm{H}$ experiences a large welfare cost of 5.54 percent, while $\mathrm{F}$ obtains a welfare gain of 0.85 percent 22

Comparing the $\mathrm{H}$ region outcomes as an open economy (first two columns of Table 4) v. closed economy (last two columns) under the same 31 percent capital tax rate, we find that $\mathrm{H}$ in autarky experiences an increase in the present value of its primary balance of 22.2 percentage points, more than twice as large as in the open-economy case. The welfare loss is nearly the same (5.53 percent), but normalizing by the amount of revenue generated, $\mathrm{H}$ is much better off in autarky. Another way to see this is to consider the value of $\tau_{K}$ for $\mathrm{H}$ as a closed economy that yields the same 9 extra percentage points of present value of the primary balance that $\mathrm{H}$ attains as an open economy with $\tau_{K}=0.3$. As Figure 2 shows, $\mathrm{H}$ under autarky can do this with a 23.5 percent tax rate, which carries a much smaller welfare cost than the 5.54 percent loss as an open economy. This shows again that if fiscal austerity focuses on capital taxes, $\mathrm{H}$ would be much better off under autarky, and hence it has strong incentives to move in that direction.

The impact and long-run effects on key macro-aggregates in both regions are shown in the bottom of Table 4 . The corresponding transition paths as the economies move from the pre-crisis steady state to the new steady state are illustrated in Figure 3. In the $\mathrm{H}$ region, the increase in $\tau_{K}$ causes a steady drop in $k$ over time to a level 20.5 percent below the pre-crisis level, while in the F region $k^{*}$ rises gradually to a level 3 percent higher than in the pre-crisis equilibrium. Capacity utilization falls sharply initially at home. We show below that this drives the higher elasticity of the base of capital income taxation. Initially, labor increases in $\mathrm{H}$ and falls in $\mathrm{F}$, but this pattern

\footnotetext{
${ }^{22}$ Welfare effects are computed as in Lucas (1987), in terms of a percent change in consumption constant across all periods that equates lifetime utility under a given debt shock and tax policy change with that attained in the pre-fiscal-crisis steady state. We report the overall effect, which includes transitional dynamics across the pre- and post-crisis steady states, as well as a comparison across steady states exclusive of transitional dynamics.
} 
reverses during the transition to steady state because of the lower (higher) capital stock in the $\mathrm{H}$ (F) region in the new steady state. As a result of the lower capital and labor, output in $\mathrm{H}$ contracts by 11 percent in the long-run, underscoring efficiency losses due to the capital tax increase and the costs of the fiscal adjustment.

The $\mathrm{H}$ region increases its net foreign asset position (NFA) by running substantial trade surpluses $(t b / y)$ in the early stages of transition, while $\mathrm{F}$ decreases its NFA position by running trade deficits. Hence, $\mathrm{H}$ is saving to smooth out the cost of the efficiency losses, as output follows a monotonically decreasing path. Still, utility levels are lower than when H implements the same capital tax under autarky, because of the negative cross-country spillovers.

The transitional dynamics of fiscal variables are plotted in Figure 4 . In the $\mathrm{H}$ region, tax revenue from capital income increases almost immediately to a higher constant level when $\tau_{k}$ rises, while the revenues from labor and consumption taxes decline both on impact and in the long run. Labor and consumption tax rates are not changing, but both tax bases fall on impact and then decline monotonically to their new, lower steady states. The primary fiscal balance and total revenue both rise initially but then converge to about the same levels as in the pre-crisis stationary equilibrium. For the primary balance, this pattern is implied by the pattern of the total revenue, since government expenditures and entitlements are held constant. For total revenue, the transitional increase indicates that the rise in capital tax revenue more than offsets the decline in the revenue from the other taxes in the transition, while in the long-run they almost offset each other exactly. This is possible because the change in $\tau_{K}$ to 0.31 is on the increasing side of the Laffer curve (see Figure 2), and in fact it is the maximum point of the curve. Hence, this capital tax hike does not reduce capital tax revenues. At higher tax rates the opposite occurs, and total revenues converge to a steady state lower than the pre-crisis level (e.g. with $\tau_{K}=0.45$ total revenue falls to a new steady state 7 percent below the pre-crisis level).

The public debt dynamics in the bottom-right panel of Figure 4 shows that on impact, government debt in the $\mathrm{H}$ region responds to the 31 percent tax rate by increasing 9 percentage points, reflecting the extra initial debt that can be supported at the higher capital tax rate (recall 9 percentage points is also what Figure 2 shows for $\tau_{K}=0.31$ ). Since the primary fiscal balance 
rises on impact and then declines monotonically, the debt ratio also falls monotonically during the transition, and converges to a ratio that is actually about 3 percentage points below the pre-crisis level. Hence, the debt shock is completely undone by the capital tax hike in the long-run. If $\mathrm{H}$ implements the same tax hike under autarky, it generates significantly larger revenues and primary balances, and hence the debt ratio increases more initially and converges to a higher steady state of 10 percentage points above the pre-crisis level. This is again a reflection of the cross-country externalities faced by $\mathrm{H}$ as an open economy, since equally-sized tax hikes produce significantly higher revenues under autarky.

The cross-country externalities are also reflected in the fiscal dynamics of the F region shown in Figure 4. Maintaining revenue neutrality (in present value) still allows both its revenue and primary balance to fall initially, while in the long run both converge to very similar levels as in the pre-crisis steady state. Removing the labor tax adjustment in $\mathrm{F}$ that maintains revenue neutrality, the present value of its primary balance as a share of GDP would increase by 11.4 percentage points relative to the pre-crisis ratio, and both its revenue and primary balances would be higher than in the plots shown in Figure 4. The welfare gain, however, would be negligible instead of 0.85 percent in lifetime consumption.

This 0.85 percent welfare gain that $\mathrm{F}$ obtains because of the positive externalities from the unilateral capital tax hike in $\mathrm{H}$ is largely overlooked in current discussions of fiscal adjustment in Europe. $\mathrm{H}$ can raise more revenue by increasing $\tau_{K}$ along the upward-sloping region of its dynamic Laffer curve, but its ability to do so is significantly hampered by the adverse externality it faces due to the erosion of its tax bases. In F, the same externality indirectly improves government finances, or reduces the distortions associated with tax collection, and provides it with an unintended welfare gain.

\section{The Roles of Endogenous Utilization and Limited Tax Allowance}

We stated earlier that a key feature of the model is that it introduces endogenous capital utilization in order to capture the observed elasticity of the capital tax base to changes in capital tax rates, in contrast with standard dynamic equilibrium models without utilization in which this elasticity is unrealistically low. In addition, we noted that the interaction with a limited tax 
allowance for depreciation was also critical for this purpose. To demonstrate these arguments, we compare dynamic Laffer curves for capital taxes under the following three senarios (see Figure 5): (A) a standard neoclassical case with exogenous utilization and a full depreciation allowance (using $\theta=1$ and shown as a dotted line); (B) the same neoclassical model but a limited depreciation allowance (using $\theta=0.22$, shown as a dashed line); (B) the baseline symmetric calibration of our model with both endogenous utilization and a limited depreciation allowance (using again $\theta=0.22$, shown as a solid line). All other parameter values are the same across all these cases.

In case $(\mathrm{A})$, the dynamic Laffer curve is nearly-linearly increasing in the $0.2-0.45$ domain of capital tax rates plotted. Moreover, we verified that this Laffer curve continues to be increasing even when we extend the capital tax rate to 0.9 . This is similar to the results obtained by Trabandt and Uhlig (2010) ) in a closed-economy setting. They found that present-value Laffer curves of capital tax revenue either become decreasing at very high tax rates (if the interest rate for discounting is kept constant) or are actually non-decreasing (discounting with equilibrium interest rates). This behavior of the capital tax Laffer curves follows from the fact that the capital stock is predetermined at any given date, and has a low elasticity in the short run. This allows the government to raise substantial revenue over the transition period when increasing the capital tax rate, since the capital stock declines gradually, and this higher transitional tax revenue dominates the fall in steady-state tax revenue, resulting in a non-decreasing dynamic Laffer curve.

Introducing the limited depreciation allowance without endogenizing the utilization choice (Case B) has two effects. First, it increases the effective rate of taxation on capital income, and thus weakens the incentive to accumulate capital and lowers the steady-state capital-output ratio and tax bases. Second, it has a positive impact on revenue by widening the capital tax base. The latter effect dominates the first when the capital tax rate is small (in the $0.2-0.33$ range), resulting in slightly higher dynamic Laffer curve values than in (A), while the opposite holds when the capital tax rate is high (above 0.33), resulting in sharply lower dynamic Laffer curve values than in (A).

In case $(\mathrm{C})$ the tax allowance is again limited but now capacity utilization is an endoegenous choice. This introduces effects that operate via distortions on efficiency and the ability to raise revenue. On the side of tax distortions, it is clear from equation (18) that endogenous utilization 
adds to the efficiency costs of capital income taxation, by introducing a wedge between the marginal cost and benefits of capital utilization. On the revenue side, endogenous utilization allows agents to make adjustments in effective capital, and thus alters the level of taxable capital income (even though the capital stock is predetermined). Hence, when utilization falls in response to increases in capital tax rates, it also weakens the government's ability to raise capital tax revenue. These effects lead to a bell-shaped dynamic Laffer curve that has more curvature and is significantly below those in scenarios (A) and (B). Thus, endogenous utilization makes capital taxes more distorting and weakens significantly the revenue-generating capacity of capital taxes 23

The effects of endogenous utilization and limited depreciation allowance on dynamic Laffer curves identified above have significant implications for the elasticity of the capital income tax base with respect to the capital tax. In particular, the combination of endogenous utilization and limited depreciation allowance is what allowed us to calibrate the model so as to obtain a short-run elasticity consistent with empirical estimates. As documented earlier, the empirical literature finds estimates of the short-run elasticity of the capital tax base in the 0.1-0.5 range. Table 5 reports the model's comparable elasticity estimates and the impact effects on output, labor and utilization, again for scenarios (A), (B) and (C). The neoclassical model with or without limited depreciation allowance (cases A and B) yields negative short-run elasticities (i.e. the capital tax base rises in the short run in response to capital tax rate increases). The reason is that labor supply rises on impact due to a negative income shock from the tax hike. Given that the capital stock is fixed, output rises on impact, and thus taxable labor and capital income both rise, producing an elasticity of the opposite sign than that found in the data. In contrast, the model with endogenous utilization (case C), generates a decline in output on impact due to a substantial drop in the utilization rate, despite the rise in labor supply. With the calibrated value of $\eta=0.2$, which is also the same used in cases (A) and (B), the model generates a short-run elasticity of 0.29 , which is about the midpoint of the range of empirical estimates.

It is worth noting also that with exogenous utilization it is not possible to obtain a capital tax base elasticity in line with empirical evidence even by re-calibrating the value of $\eta$, unless $\eta$ itself is

\footnotetext{
${ }^{23}$ Note that removing the limited depreciation allowance from case $(\mathrm{C})$ still results in a Laffer curve significantly below those of cases (A) and (B). It is also flatter and increasing for a wider range of capital taxes than case (C).
} 
set unrealistically low. The model-predicted short-run elasticity of the capital tax base is negative for $\eta>1$, and it becomes positive and higher than 0.1 only for $\eta<0.1$. This is significantly below the empirically relevant range of 1-2.5 documented in the calibration section. Moreover, at the value of $\eta=2$ obtained in our baseline calibration, the model without utilization choice yields a capital tax base elasticity of -0.031 .

\section{Dynamic Laffer Curves of Labor Tax Rates}

Figures 6, 7 and 8 and Table 6] show the results for unilateral changes in H's labor tax rate analogous to the capital tax rate changes we have examined. The results are more optimistic in terms of the ability of $\mathrm{H}$ to raise revenue and restore fiscal solvency in response to the debt shock. The open-economy Laffer curve for $\tau_{L}$ (Figure 6) is considerably steeper than for the capital tax rate, and it peaks at a tax rate of 0.49 with an increase in the present value of the primary balance as a share of GDP of about 0.51 , well above the 0.22 needed to offset the debt shock. The labor tax rate that $\mathrm{H}$ as an open economy needs to support the 0.88 debt ratio is therefore much lower, at about 38 percent, and under autarky is just a little lower. This is because the open- and closedeconomy Laffer curves are much closer to each other than in the case of the capital tax experiment, even though again the closed-economy curve is higher and shifted to the right. This suggests that international spillovers of tax policies are weaker with labor than with capital taxes, as we confirm below.

Table 6 compares steady-state results for an increase in the labor tax that raises H's present value of the primary fiscal balance by roughly the same magnitude as in the capital tax experiment of Table 4 (i.e. 9 percentage points). This is done so as to make the results in the two Tables comparable. The required increase in $\tau_{L}$ is only one percentage point, from 35 to 36 percent. This yields much smaller declines in steady-state output, consumption, capital and the investment rate than in the capital tax case. The welfare cost is also much smaller at 0.91 percent. Comparing $\mathrm{H}$ as a closed v. open economy, the gap in the increase of the present value of the primary balance is almost negligible in the labor tax case, in contrast with the wide gap obtained for the capital tax.

Taken together these findings are consistent with two familiar results from tax analysis in representative-agent models, which emphasize the efficiency costs of tax distortions. First, the 
capital tax rate is the most distorting tax. Second, in open-economy models, taxation of a mobile factor (i.e. capital) yields less revenue at greater welfare loss than taxation of the immobile factor (i.e. labor). This is in line with our results showing that the cross-country tax externalities are strong for capital taxes but weak for labor taxes. With capital taxes, $\mathrm{H}$ as an open economy cannot restore fiscal solvency after a debt shock of 22 percentage points, while under autarky it can do it with a capital tax of about 31 percent at a welfare cost of 5.53 percent. In contrast, with labor taxes, $\mathrm{H}$ can offset the same debt shock with about a 38 percent labor tax either as an open economy or under autarky, with a much smaller welfare cost of 2.43 percent. On the other hand, our results also indicate that it is plausible for cross-country tax externalities to be significant even for labor taxes. Figure 6 indicates that for debt shocks larger than 40 percentage points and/or pre-debtshock labor taxes higher than 40 percent, the cross-country externalities would be nontrivial and in the same direction as those observed in the capital tax analysis.

Asymmetric Regions: GIIPS, EU10

Up to this point, we have focused only on experiments that use the symmetric baseline calibration. Now we study the effects of heterogeneity in region size. Table 7 shows results for tax policy adjustments for each country in the GIIPS acting unilaterally. In each scenario, we solve the model resetting the parameter controlling the relative size of the two regions so that $\mathrm{H}$ has the size of the corresponding GIIPS country relative to the eurozone (shown in the second column of the Table). Intuitively, each country in GIIPS treated in this way becomes much smaller, and the effect of a domestic tax change on international prices is correspondingly smaller. This in turn means that the impact on domestic capital outflow is greater, and thus the ability to raise revenue weakens considerably. This is reflected in the peaks of the Laffer curves listed in the last two columns of Table 7, which show the maximum increase in the present discounted value of the primary balance that each GIIPS country can obtain individually using capital or labor taxes.

The results in the Table also show that none of the GIIPS countries can restore fiscal solvency with a capital income tax hike (i.e.the peaks of the Laffer curves are smaller than the debt shocks shown in the third column), and one of the five countries (Ireland) cannot do it even with the labor tax. Note also that Greece and Ireland experienced debt shocks that are much higher than the 
GDP-weighted GIIPS regional average of 0.3.

\subsection{Strategic Interaction in Tax Responses to Debt Shocks}

The findings from the analysis of unilateral tax changes showed that capital tax changes produce significant cross-country externalities, suggesting that there is scope for strategic interaction and potential gains from coordination in considering tax responses to restore fiscal solvency in response to debt shocks. In particular, when a region raises its capital tax, the externalities move against that region and make the other region relatively more efficient. The burden of fiscal adjustment in response to debt shocks is heavier (lighter) for the region with the higher (lower) taxes. But the governments of both regions are aware of the externalities, and thus have an incentive to engage in tax competition.

To analyze strategic interaction, we follow Mendoza and Tesar (2005) and examine the solutions to one-shot cooperative and non-cooperative games. They focused on tax reform experiments in which the present value of revenue had to remain constant, whereas here we consider games in which each region uses capital and labor taxes to respond to their corresponding debt shocks. These games are solved first using the symmetric baseline calibration in which both regions are identical, then introducing elements of heterogeneity one at a time, and finally considering two fully heterogeneous regions, one calibrated to GIIPS and the other to EU10, capturing their differences in country size, pre-debt-shock fiscal policies and trade balances, and size of debt shocks.

The formal characterization of the strategy space and the games is as follows. The strategy space is defined in terms of vectors of possible capital tax rates that the government of each region can choose. For each given pair of capital tax rates $\left(\tau_{K}, \tau_{K}^{*}\right)$ in this strategy space, we solve for the pair of labor tax rates $\left(\tau_{L}, \tau_{L}^{*}\right)$ that allows each region to increase the present value of its primary balance at the corresponding competitive equilibrium as needed to restore solvency after the debt shocks -22 percentage points for both regions in the symmetric benchmark case, and 30 for GIIPS and 18 for EU10 in the asymmetric case. The games are played once, but the payoffs are dynamic, because they take into account the full transitional dynamics from the pre-crisis competitive equilibrium to the new stationary equilibrium of under a particular set of capital and 
labor taxes in both regions.

Each region chooses its capital tax rate so as to maximize the lifetime utility of its residents taking as given the other region's taxes and subject to the constraints that: (i) the implied allocations and prices for a tax structure given by the pairs $\left(\tau_{K}, \tau_{L}\right),\left(\tau_{K}^{*}, \tau_{L}^{*}\right)$, with unchanged consumption taxes, are a competitive equilibrium; and (ii) labor taxes in each region adjust so that intertemporal government budget constraints support increases in the present value of the primary fiscal balances equal to each region's debt shock, as shown in equation (10).

The regions choose capital tax rates from values in discrete grids with $M$ and $N$ nodes for the home and foreign country respectively: $T_{K}=\left\{\tau_{K 1}, \tau_{K 2}, \ldots, \tau_{K M}\right\}$ and $T_{K}^{*}=\left\{\tau_{K 1}^{*}, \tau_{K 2}^{*}, \ldots, \tau_{K N}^{*}\right\}$. Hence, the strategy space is the set of $M \times N$ capital tax rate pairs. For each pair, we compute prices and allocations that satisfy conditions (a) and (b) and the associated welfare payoffs. The payoff function for the home's strategic choice of $\tau_{K}$ given $\tau_{K}^{*}$ is denoted $V\left(\tau_{K} \mid \tau_{K}^{*}\right)$. The corresponding foreign payoff function is denoted by $V^{*}\left(\tau_{K}^{*} \mid \tau_{K}\right)$. Given these definitions, H's reaction curve is defined by the mapping $\tau_{K}\left(\tau_{K}^{*}\right)=\arg \max _{\tau_{K}}\left[V\left(\tau_{K} \mid \tau_{K}^{*}\right)\right]$ and the one for $\mathrm{F}$ is $\tau_{K}^{*}\left(\tau_{K}\right)=\arg \max _{\tau_{K}^{*}}\left[V^{*}\left(\tau_{K}^{*} \mid \tau_{K}\right)\right]$. The Nash non-cooperative equilibrium is given by the tax rate pair $\left(\tau_{K}^{N}, \tau_{K}^{N *}\right)$ at which these reaction functions intersect. That is, $\tau_{K}^{N}=\tau_{K}\left(\tau_{K}^{N *}\right)$ and $\tau_{K}^{N *}=\tau_{K}^{*}\left(\tau_{K}^{N}\right)$.

A cooperative equilibrium is defined as the pair $\left(\tau_{K}^{C}, \tau_{K}^{C *}\right)$ such that: (1) it satisfies properties (i) and (ii), and (2) the pair maximizes the payoff of a utilitarian European-wide social planner given by the weighted sum of the two regions' payoffs $\lambda V\left(\tau_{K} \mid \tau_{K}^{*}\right)+(1-\lambda) V^{*}\left(\tau_{K}^{*} \mid \tau_{K}\right)$ for an arbitrary weight $\lambda$ subject to participation constraints that require each region to be at least as well off as under the Nash equilibrium: $V\left(\tau_{K}^{C} \mid \tau_{K}^{C *}\right) \geq V\left(\tau_{K}^{N} \mid \tau_{K}^{N *}\right)$ and $V^{*}\left(\tau_{K}^{C *} \mid \tau_{K}^{C}\right) \geq V^{*}\left(\tau_{K}^{N *} \mid \tau_{K}^{N}\right)$. There can be several cooperative equilibria supported by different $\lambda^{\prime} s$, and the set of all cooperative equilibria determines the core of the players' contract curve. Note that these cooperative equilibria are still tax-distorted competitive equilibria, because cooperation internalizes the effects of the international tax externalities but does not remove domestic tax distortions themselves.

Figure 9 shows the reaction functions in $\left(\tau_{K}, \tau_{K}^{*}\right)$ space and identifies the Nash and pre-crisis equilibria in the game with symmetric regions. The "Nash" column in Table 8 shows the corresponding tax rates, welfare outcomes, and changes in the present value of primary balance. Both 
reaction functions have a negative slope because of the positive externalities that one country experiences if the other chooses a higher tax rate. For instance, the higher the capital tax rate in F, the lower the optimal capital tax choice in $\mathrm{H}$, because it allows $\mathrm{H}$ to reduce tax distortions while still maintaining fiscal solvency. Starting from identical tax rates on capital of 0.20 pre-crisis, Nash competition results in the familiar "race to the bottom" in capital taxes, to 0.08. Labor taxes increase from 0.35 to 0.44 and welfare declines relative to the pre-crisis equilibrium by 1.63 percent.

Note that the welfare effects from the outcome of tax competition in response to debt shocks involve two opposing effects. The first is that countries must raise revenue in response to the debt shock. The second is that by competing in tax rates the regions are effectively reforming their tax systems relative to pre-crisis tax rates (countries are optimally choosing labor and capital taxes to raise the required revenue at the lowest efficiency cost). In principle it could be possible for the gains from the latter to outweigh the costs of the former, but in our experiments using debt shocks of the observed magnitudes this does not happen.

Consider next the symmetric cooperative equilibrium solutions shown in Figure 9. Because of symmetry, we focus on the cooperative outcome for equal country weights (see column Cooperative in Table 8). In the cooperative equilibrium, the capital tax rate is higher than under Nash: 0.12 versus 0.08, and the labor tax rate is lower: 0.42 versus 0.44. Cooperation allows countries to commit to higher capital taxes relative to Nash and avoid painful increases in labor taxes, which reduces the welfare cost of tax austerity to respond to the debt shocks from 1.63 to 1.45 percent (i.e. the welfare gain from cooperation is about 0.18 ).

While tax coordination helps prevents welfare-reducing strategic interaction, the welfare costs of adjusting taxes to offset debt shocks are still quite large in both Nash and cooperative outcomes. Relative to the pre-crisis tax rates, capital taxes are lower and labor taxes are higher in the Nash equilibrium after the debt shocks for two reasons. First, capital tax rates are lower because governments wish to reduce the tax that is most distorting in terms of welfare cost per unit of revenue (i.e. the capital tax). Second, in an open economy governments have the incentive to undercut other countries' tax rates in an effort to attract foreign capital and thereby increase the tax base. Since both countries are attempting the same strategy, the outcome is lower capital tax rates and 
higher labor tax rates than is optimal under cooperation.

To highlight the impact of the strategic reaction by the foreign country on the home country, we conduct two additional experiments. One is the "Autarky" experiment, which shows the effects of fiscal adjustments to meet the debt shock in a closed economy. Note that under symmetry, the autarky outcome is identical to the cooperative outcome above by construction. Thus, the closed economy model will underestimate the welfare loss from the debt shock. The other is the "Unilateral" experiment, which corresponds to the unilateral Laffer curve experiment illustrated in Figure 2, As in that Figure, we assume that only $\mathrm{H}$ experiences the debt shock, and the foreign country adjusts its labor tax rate to maintain revenue neutrality but does not behave strategically. $\mathrm{H}$ chooses both capital and labor tax rates lower than those in the Nash equilibrium. Consequently, the welfare cost of the debt shock for the home country is smaller in the unilateral case than in the Nash case: 0.67 versus 1.63. This outcome, however, is not sustainable once we relax the assumption that the foreign country is a passive player and allow it to respond optimally.

The last column of Table 8 reports the Nash outcome implied by the neoclassical model with exogenous utilization $(\theta=0.22)$. Relative to the benchmark results in the Nash column, the neoclassical model underestimates the tax competition effect on capital taxation. When the adjustment in capital is sluggish, the two countries can rely more heavily on capital taxation. As a consequence, they also end up with a less efficient tax system and therefore experience larger welfare losses.

We next move to the asymmetric game in which we introduce the elements of heterogeneity across the GIIPS and EU10 regions one by one. The results are reported in Table 9. Starting with country size (the second column of Table 9), tax competition benefits small countries in two ways. One is that by having a smaller impact on world prices, the small country can play off of the large country without offsetting price adjustments. Second, the smaller country faces a bigger supply of foreign capital from which the home country can steal by undercutting the capital tax rate. Indeed, the benefit of being small leads to an approximate 0.26 relative welfare benefit for the smaller $\mathrm{H}$ region relative to the bigger region. An initial trade surplus (negative NFA position) is an advantage for EU10. The initial drop in interest rates along the transition path reduces the cost of servicing external debt. This has a sizable welfare effect, with a relative gain for EU10 of 
nearly 2.5 percent. Asymmetries in initial tax rates also matter in the Nash game. Having a higher capital tax rate but lower labor and consumption taxes benefits GIIPS at the expense of the EU10 in the Nash game (the higher the capital tax rate initially, the more to gain from the race to the bottom) ${ }^{24}$ Finally, facing a larger debt shock places GIIPS at a disadvantage in the Nash game. The impact of the differential debt shock is large: the GIIPS region suffers a welfare loss of 3.5 percent while the EU10 suffers only 0.59 percent. The last column of Table 9 reports the outcome of putting all of these differential factors altogether. GIIPS undercuts EU10 in capital tax rates: 0.07 versus 0.09 , but given its larger debt shock, GIIPS still experiences a substantial welfare loss of 1.55 percent, and EU10 experiences a welfare loss of 1.13 percent, relative to their pre-crisis levels.

Table 10 reports Nash, cooperative and autarky outcomes for the fully asymmetric game. The Nash column repeats the results from the final column of Table 9. The important message of Table 10 is the comparison of the Nash equilibrium with the cooperative equilibrium and the autarky exit option. Two points are worth noting. First, both regions are hurt by tax competition and would prefer cooperation to Nash. However, in the event cooperation fails, GIIPS prefers to exit while EU10 prefers tax competition to exit. Even in the case where the lion's share of the gains from cooperation are allocated to GIIPS (case 1), GIIPS prefers the autarky outcome. This means that the international externalities work against GIIPS and tend to favor EU10. Failure to take these international externalities into account undermines the sustainability of the union.

\section{Conclusions}

Public debt ratios surged between 2008 and 2011 in many industrial countries, raising serious questions about fiscal solvency and the need for fiscal adjustment. In the eurozone in particular, public debt increased by a GDP-weighted average of 30 percentage points in the GIIPS region and in the EU10 by 18 percentage points. If, in the presence of these large debt shocks, defaults are to be averted (i.e. fiscal solvency maintained) and the eurozone countries are to remain fully integrated in goods and asset markets, three key questions arise. First, is tax-driven adjustment feasible (i.e. can it yield increases in the present value of the primary fiscal balances that match

\footnotetext{
${ }^{24}$ The pre-debt-crisis consumption-leisure tax wedges are 0.46 for EU10 v. 0.41 for GIIPS.
} 
the higher debt ratios)? Second, how do different tax-adjustment policies using capital or labor taxes differ in terms of revenue, macroeconomic dynamics, cross-country externalities, and welfare costs? Third, what are the implications of strategic interaction, and the benefits of coordination, in the tax-adjustment response to debt changes in economies that trade freely in goods and assets?

The workhorse Neoclassical model with exogenous long-run growth widely used for quantifying the effects of tax policies in the literature is poorly suited to answer these questions, because it underestimates the elasticity of the capital tax base to changes in capital taxes. This is due to the fact that the capital stock is pre-determined at any given date, and adjusts slowly over the long run, and also to the standard assumption of a 100-percent depreciation tax allowance. As a result, models of this class tend to produce rosy estimates of the effectiveness of capital tax hikes for raising tax revenues and underestimate the significance of cross-country externalities.

In contrast, in this paper we answer the above questions using a two-country, dynamic general equilibrium model that deviates from the workhorse Neoclassical model in two key respects. First, it allows for endogenous utilization of capital, which allows agents to adjust taxable capital income much quicker in response to capital tax changes. Second, it introduces a limited depreciation tax allowance, which is in line with the actual treatment in tax codes that apply this allowance to taxes levied to business incomes, not capital income accruing to individuals (e.g. dividends, capital gains), and do not apply it to residential capital. These two features of the model make capital income taxes more distortionary than in the Neoclassical model, and also lower signficantly the ability of the government to raise capital income tax revenues. As a result, a reasonable calibration of the model features a short-run elasticity of the capital tax base around the midpoint of empirical estimates.

We calibrate the model to data for eurozone countries and find striking results. Raising capital taxes unilaterally is not a feasible strategy for restoring fiscal solvency in response to the observed debt shocks. The dynamic Laffer curve that maps capital taxes into changes in the present value of the primary fiscal balance peaks far below the required increment. Labor taxes can do it, but in both cases the tax hikes entail large welfare costs. Moreover, capital tax adjustments induce large cross-country externalities, which favor the countries with less pressure to raise capital taxes 
(i.e.the EU10). In addition, in both scenarios GIIPS can offset the observed debt shocks at lower tax rates and welfare costs under autarky, which in the model provides them with a strong incentive to move in that direction or default on their debt obligations.

Non-cooperative Nash competition, which involves choosing the optimal pairs of capital and labor taxes to restore fiscal solvency in response to the observed debt shocks, yields the well-known race to the bottom in capital tax rates. When countries can adjust capital and labor taxes, the tax structure shifts sharply toward lower capital and higher labor taxation. In representativeagent models of the class we study this induces efficiency gains, reducing the welfare cost of fiscal adjustment. The race ends with small positive capital taxes and higher labor taxes relative to precrisis rates, but the former are too low and the latter too high because countries do not internalize the international externalities of their tax policies. Cooperation internalizes these externalities, and thus reduces the size of the cut in capital taxes and hike in labor taxes. This makes fiscal adjustment slightly less costly, but even in this case the welfare cost of the tax adjustments that restore fiscal solvency remains large.

The costs of adjusting to the large debt shocks are lower when regions or countries are assumed to be able to choose the best mix of their own capital and labor taxes acting unilaterally and assuming the other countries remain passive. These results are not sustainable, however, because they negate the strong incentives for strategic interaction. Moreover, the costs of implementing the best mix of capital and labor tax changes to restore fiscal solvency are lower under autarky than those of the Nash and Cooperative games for the GIIPS region, but higher for the EU10 region. Hence, the GIIPS region is left with an incentive to move away from full economic integration.

The analysis of this paper has clear implications for current policy. Despite the fact that the European nations have closely integrated goods and financial markets, policy discussions have proceeded largely without taking into account international ramifications of domestic tax policy adjustments. Economists have pointed out a number of factors that could give highly-indebted European countries incentives to exit the eurozone; a depreciation of the currency could produce an export boom and reduce unit labor costs, removal of the Maastricht debt and deficit targets could enable countries to adopt more expansive monetary and fiscal policies, and default on external 
debt could relax (at least temporarily) the country's budget constraint. This paper identified and quantified another factor that can undermine incentives to remain in the eurozone significantly: the fiscal externalities from tax austerity that work against the GIIPS region. These factors deserve careful consideration in discussions of fiscal austerity and fiscal sustainability. 


\section{References}

Abiad, Abdul and Jonathan D. Ostry, 2005. "Primary Surpluses and Sustainable Debt Levels in Emerging Market Countries." IMF Policy Discussion Papers, 104(1).

Auray, Stephane, Aurelien Eyquem, and Paul Gomme, 2013. "A Tale of Tax Policies in Open Economies." mimeo, Department of Economics, Concordia University.

Bohn, Henning, 2007. "Are Stationarity and Cointegration Restrictions Really Necessary for the Intertemporal Budget Constraint?" Journal of Monetary Economics, 54(7): 1837-1847.

Carey, David and Harry Tchilinguirian, 2000. "Average Effective Tax Rates on Capital, Labour and Consumption." OECD Economics Department Working Papers: 258.

Dwenger, Nadja and Viktor Steiner, 2012. "Profit Taxation and the Elasticity of the Corporate Income Tax Base: Evidence from German Corporate Tax Return Data." National Tax Journal, 65(1): 117-150.

Eggert, Wolfgang, 2000. "International Repercussions of Direct Taxes." FinanzArchiv, 57(1): $106-125$.

Ferraro, Dominico, 2010. "Optimal Capital Income Taxation with Endogenous Capital Utilization." mimeo, Department of Economics, Duke University.

Frenkel, Jacob A., Assaf Razin, and Efrain Sadka, 1991. International Taxation in an Integrated World. MIT Press.

Greenwood, Jeremy, Zvi Hercowitz, and Gregory W. Huffman, 1988. "Investment, Capacity Utilization, and the Real Business Cycle." The American Economic Review, 78(3): pp. 402-417, URL http://www.jstor.org/stable/1809141.

Gruber, Jonathan and Joshua Rauh, 2007. In "Taxing Corporate Income in the 21st Century," Cambridge University Press.

House, Christopher L. and Matthew D. Shapiro, 2008. "Temporary Investment Tax Incentives: Theory with Evidence from Bonus Depreciation." American Economic Review, 98(3): 737-68, URL http://www.aeaweb.org/articles.php?doi=10.1257/aer.98.3.737.

Kellerman, Christian and Andreas Kammer, 2009. "Deadlocked European Tax Policy: Which Way Out of the Competition for Lowest Taxes?" European Tax Policy: 127-141.

King, Robert G., Charles I. Plosser, and Sergio T. Rebelo, 1988. "Production, Growth and Business Cycles: I. The Basic Neoclassical Model." Journal of Monetary Economics, 21(2): $195-232$.

Klein, Paul, Vincenzo Quadrini, and Jose-Victor Rios-Rull, 2005. "Optimal TimeConsistent Taxation with International Mobility of Capital." B.E. Journal of Macroeconomics: Advances in Macroeconomics, 5(1): 1-34.

Mendoza, Enrique G. and Jonathan D. Ostry, 2008. "International Evidence on Fiscal Solvency: Is Fiscal Policy Responsible." Journal of Monetary Economics, 55: 1081-1093. 
Mendoza, Enrique G. and Linda L. Tesar, 1995. "Supply-Side Economics in a Global Economy." NBER Working Paper 5086.

Mendoza, Enrique G. and Linda L. Tesar, 1998. "The International Ramifications of Tax Reforms: Supply-Side Economics in a Global Economy." American Economic Review, 88(1): $226-245$.

Mendoza, Enrique G. and Linda L. Tesar, 2005. "Why Hasn't Tax Competition Triggered a Race to the Bottom? Some Quantitative Lessons from the EU." Journal of Monetary Economics, 52(1): 163-204.

Mendoza, Enrique G., Assaf Razin, and Linda L. Tesar, 1994. "Effective Tax Rates in Macroeconomics: Cross-Country Estimates of Tax Rates on Factor Incomes and Consumption." Journal of Monetary Economics, 34(3): 297-323.

Mendoza, Enrique G., Gian Maria Milesi-Ferretti, and Patrick Asea, 1997. "On the Ineffectiveness of Tax Policy in Altering Long-Run Growth: Harberger's Superneutrality Conjecture." Journal of Public Economics, 66(2): 99-126.

Ostry, Jonathan D., Atish R. Ghosh, Karl Habermeier, Marcos Chamon, and Mahvash S. Qureshi, 2010. "Capital Inflows: The Role of Controls." Revista de Economia Institucional, 12(23).

Persson, Torsten and Guido Tabellini, 1995. "Double-Edged Incentives: Institutions and Policy Coordination." In Gene M. Grossman and Kenneth Rogoff, eds., "Handbook of International Economics," vol. 3, Elsevier, North Holland, 1973-2030.

Prescott, Edward C., 2004. "Why Do Americans Work So Much More Than Europeans." Federal Reserve Bank of Minneapolis Quarterly Review, July.

Sorensen, Peter B., 1999. "Optimal Tax Progressivity in Imperfect Labour Markets." Labour Economics, 6(3): 435-452.

Sorensen, Peter B., 2001. "Tax Coordination and the European Union: What Are the Issues?" University of Copenhagen Working Paper.

Sorensen, Peter B., 2003. "International Tax Competition: A New Framework for Analysis." Economic Analysis and Policy, 33(2): 179-192.

Trabandt, Mathias and Harald Uhlig, 2009. "How Far Are We From the Slipery Slope?" NBER Working Paper 15343.

Trabandt, Mathias and Harald Uhlig, 2010. "How Far Are We From the Slipery Slope? The Laffer Curve Revisited." European Central Bank, Working Paper Series: 1174.

Trabandt, Mathias and Harald Uhlig, 2012. "How do Laffer Curves Differ Across Countries?" BFI Paper no. 2012-001.

Turnovsky, Stephen J., 1997. International Macroeconomic Dynamics. MIT Press. 
Figure 1: Debt Shocks in the eurozone

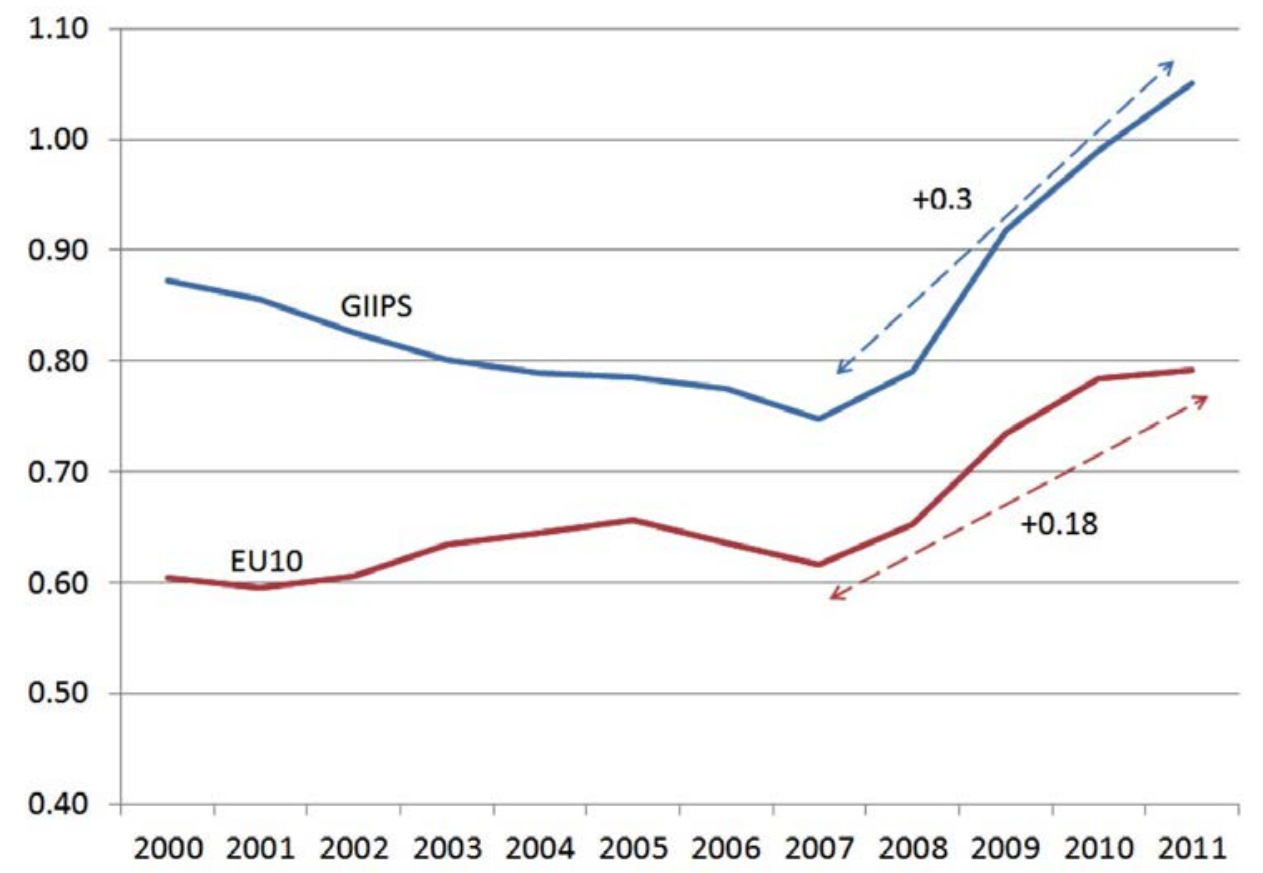


Figure 2: Dynamic Laffer Curves for the Capital Tax Rate

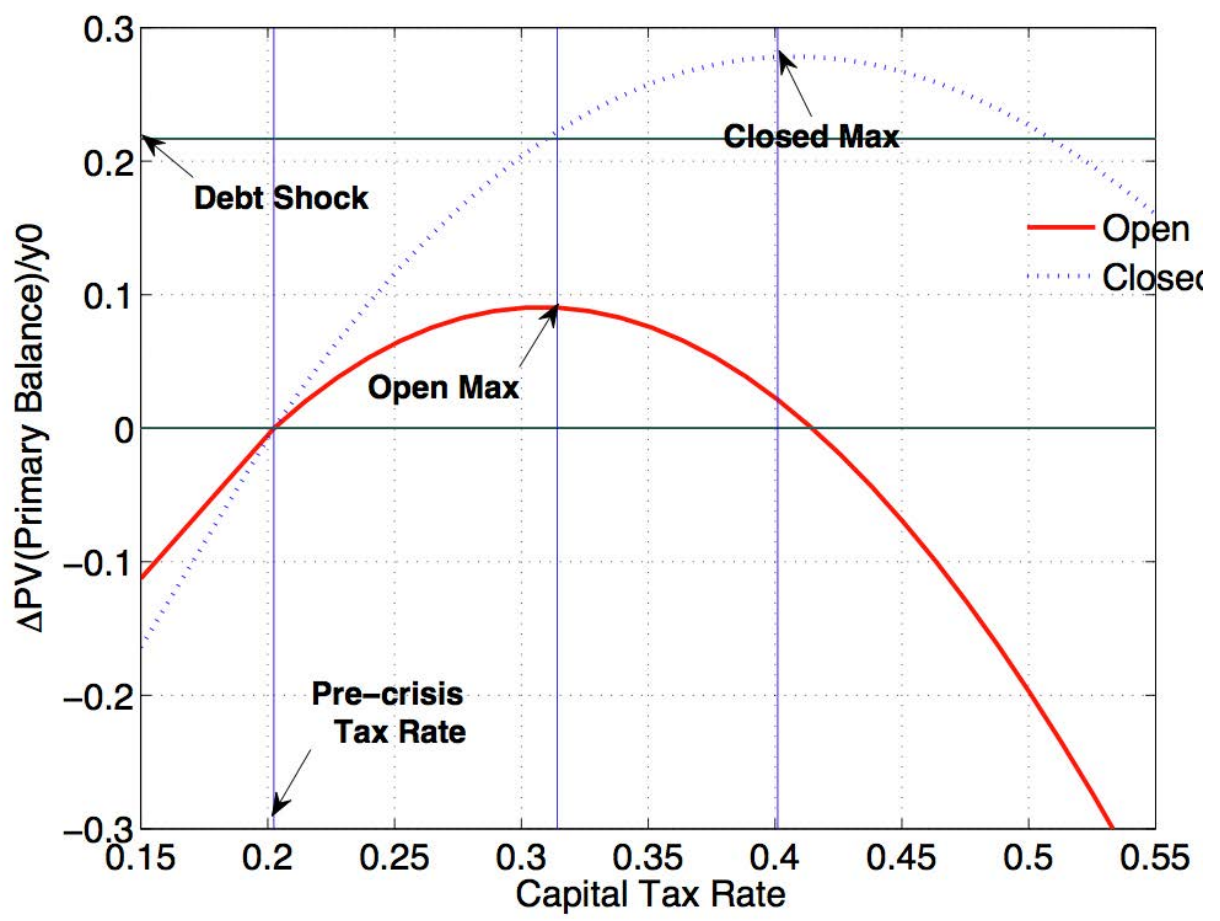

Notes: Dynamic Laffer curves plot the equilibrium present value of total tax revenue net of the equilibrium present value of government spending and transfers as a ratio of predebt-crisis output relative to the pre-debt-crisis public debt ratio when the capital tax rate changes. 
Figure 3: Macro Responses to a Capital Tax Rate Increase
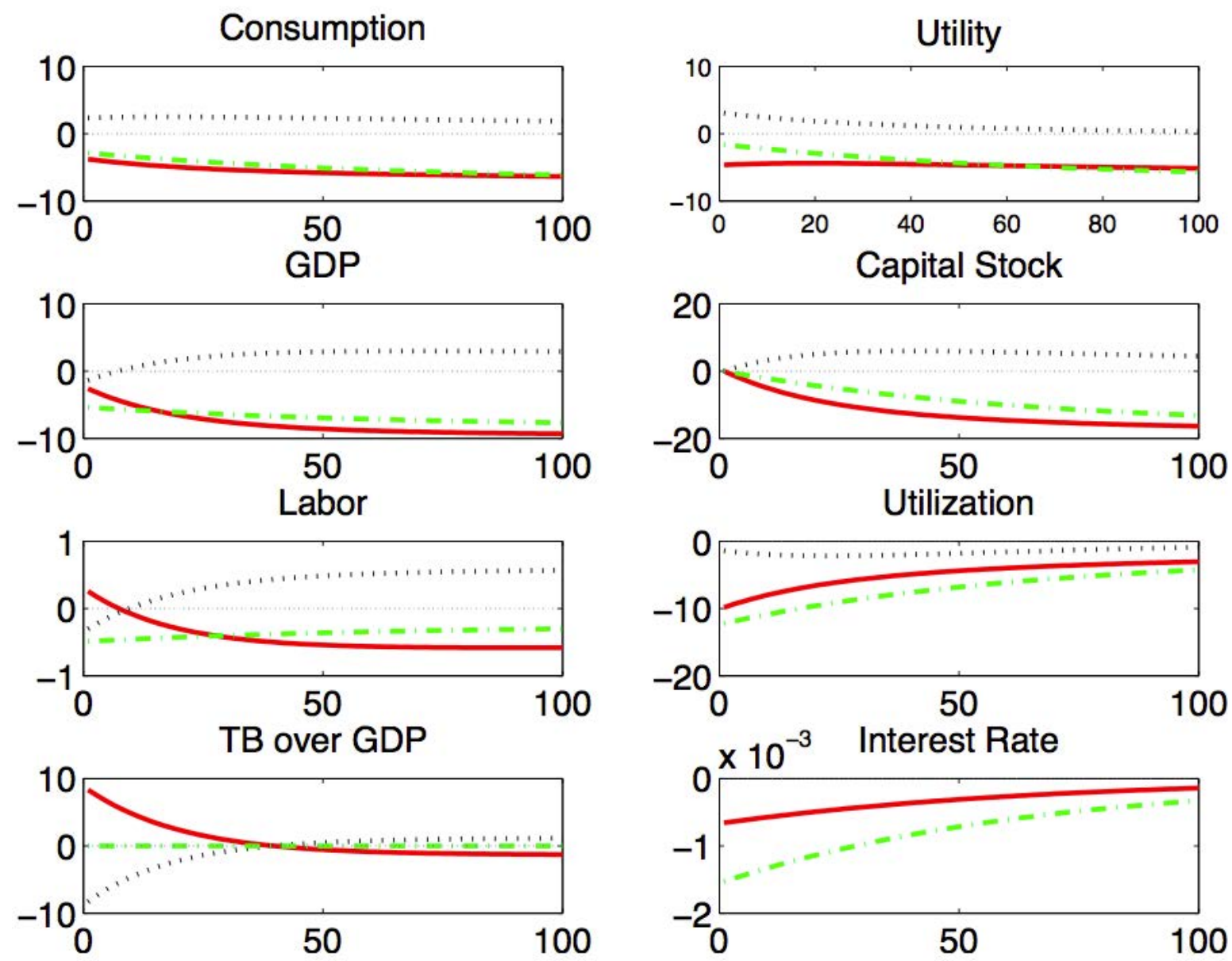

Notes: In this experiment, the foreign labor tax rate is adjusted from 0.35 to 0.32 to reserve its revenue neutrality. All variables are reported as percent changes from pre-crisis steady state except the lower panel, which are in percentage point differences from pre-crisis steady state. The solid red lines and the dotted black lines are for the home and foreign country, respectively, in the open economy. The dashed green lines are for the home country in the closed economy. 
Figure 4: Fiscal Responses to a Capital Tax Rate Increase
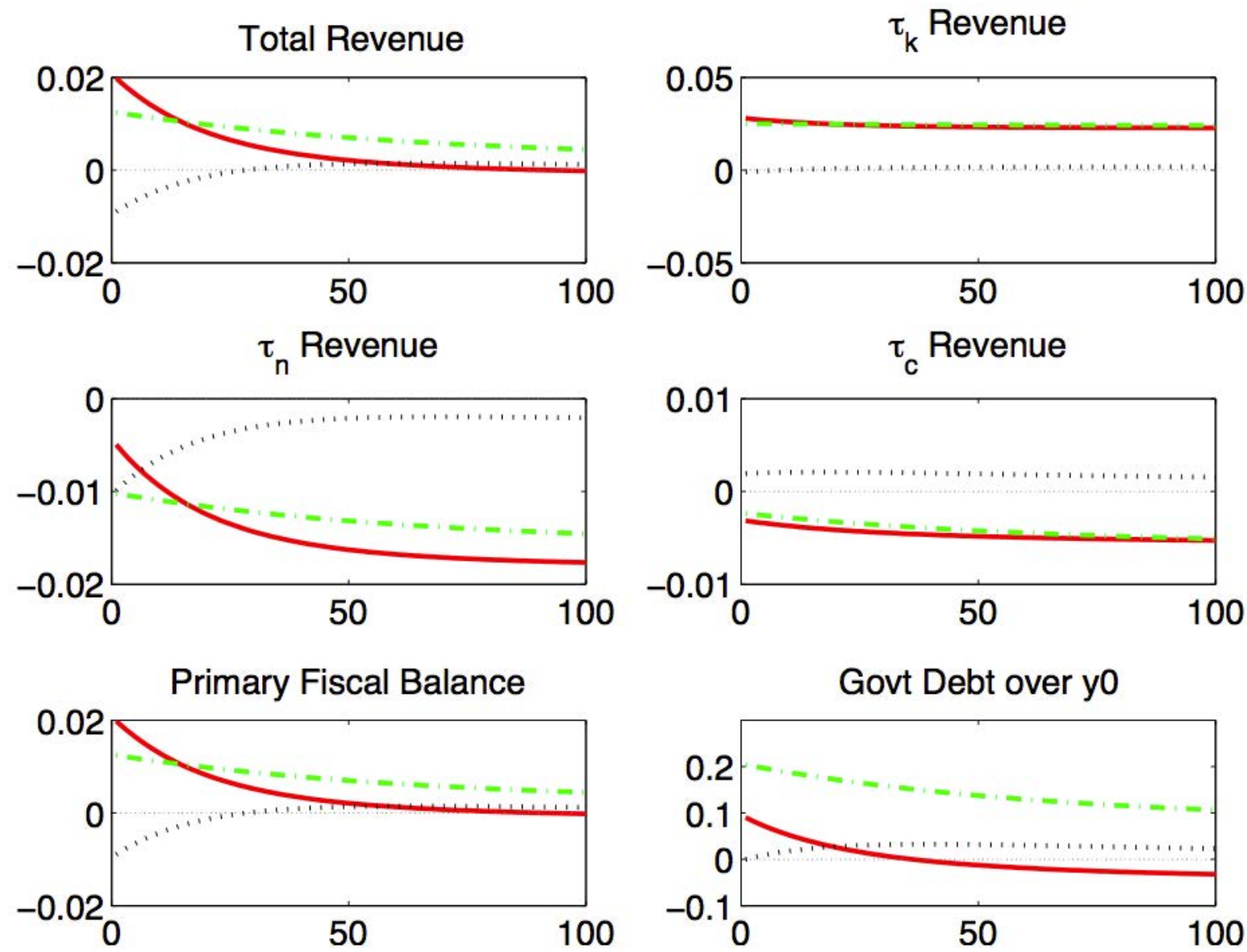

Notes: All variables are reported as changes from pre-crisis steady state levels. The solid red lines and the dotted black lines are for the home and foreign country, respectively, in the open economy. The dashed green lines are for the home country in the closed economy. 
Figure 5: Comparisons of Dynamic Laffer Curves for the Capital Tax Rate

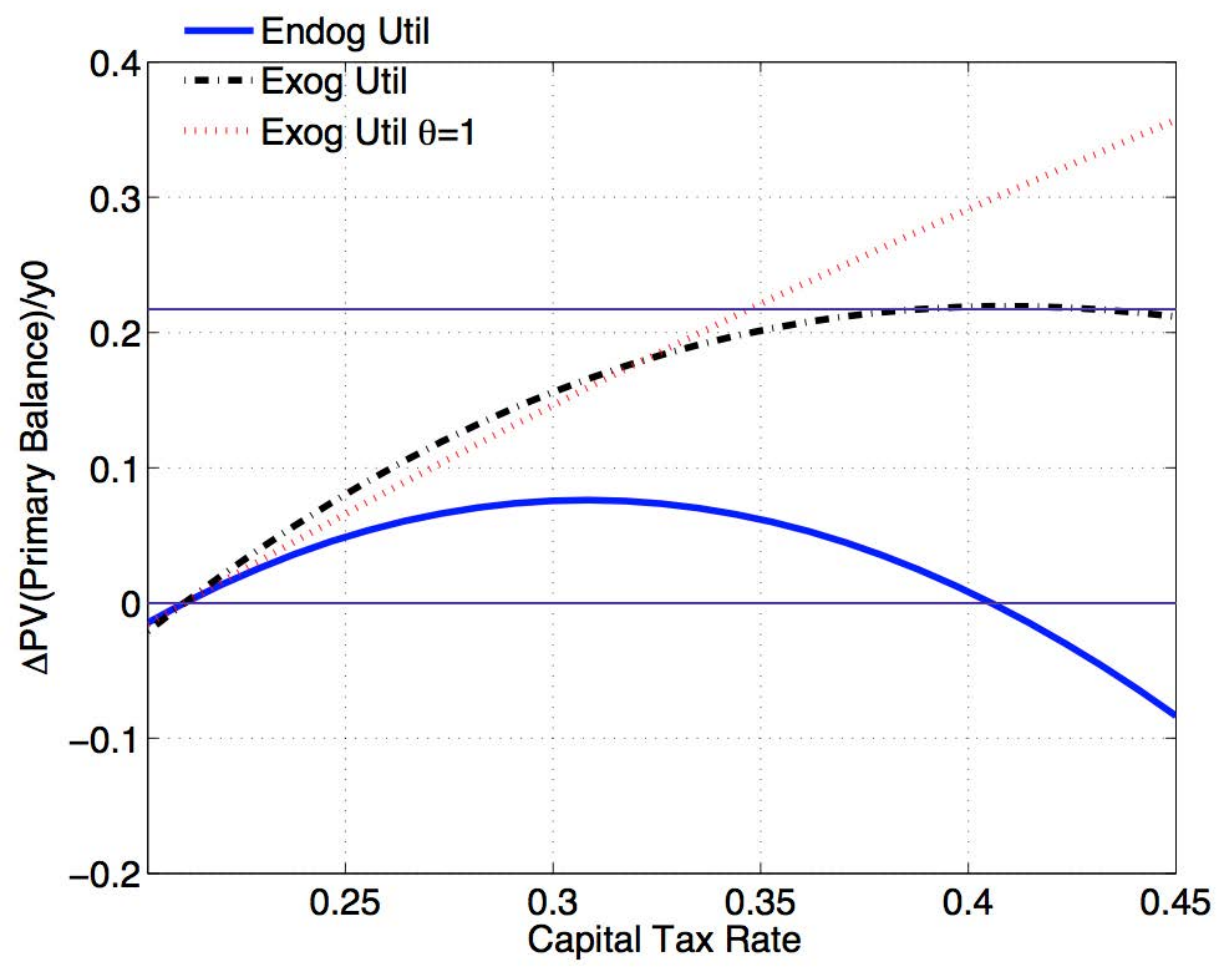

Notes: The dotted red line is for the neoclassical case with exogenous utilization and full depreciation allowance; the dashed black line is for the neoclassical case with exogenous utilization and partial depreciation allowance; the solid blue line is for the benchmark calibration with endogenous utilization and partial depreciation allowance. 
Figure 6: Dynamic Laffer Curves for the Labor Tax Rate

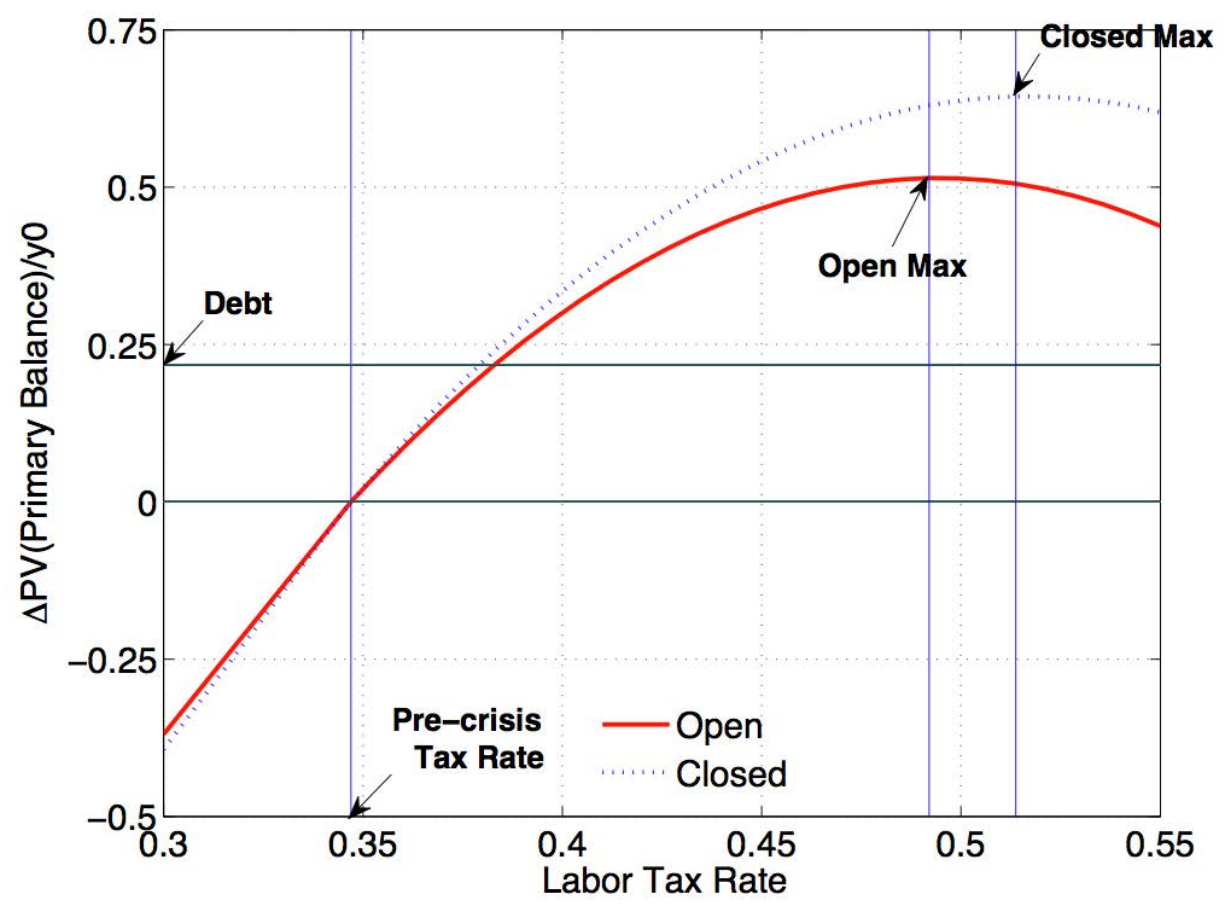

Notes: Dynamic Laffer curves plot the equilibrium present value of total tax revenue net of the equilibrium present value of government spending and transfers as a ratio of predebt-crisis output relative to the pre-debt-crisis public debt ratio when the labor tax rate changes. 
Figure 7: Macro Responses to a Labor Tax Rate Increase
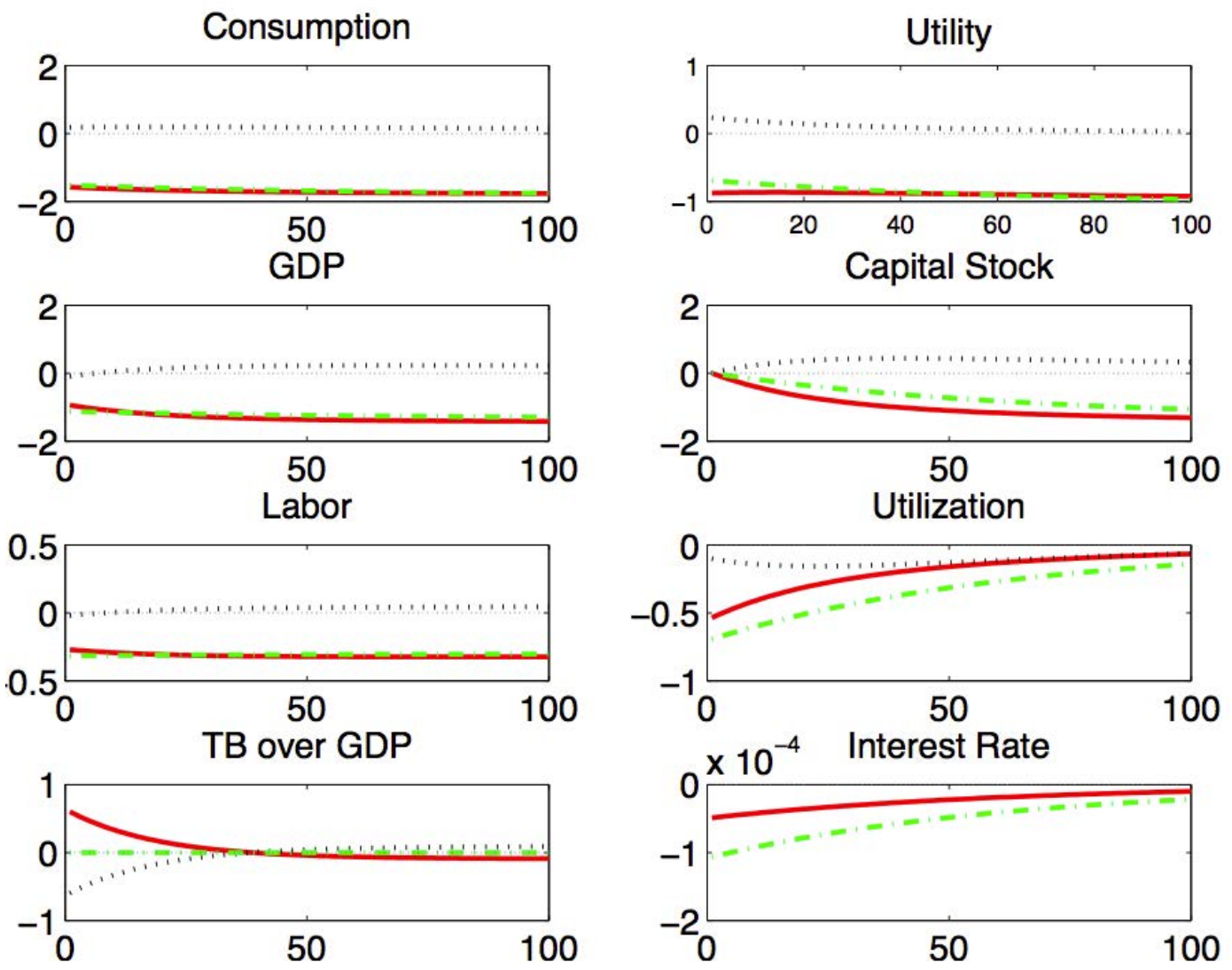

Notes: In this experiment, foreign labor tax rate is adjusted from 0.35 to 0.34 to reserve its revenue neutrality. All variables are reported as percent changes from pre-crisis steady state except the lower panel, which are in percentage point differences from pre-crisis steady state. The solid red lines and the dotted black lines are for the home and foreign country, respectively, in the open economy. The dashed green lines are for the home country in the closed economy. 
Figure 8: Fiscal Responses to a Labor Tax Rate Increase
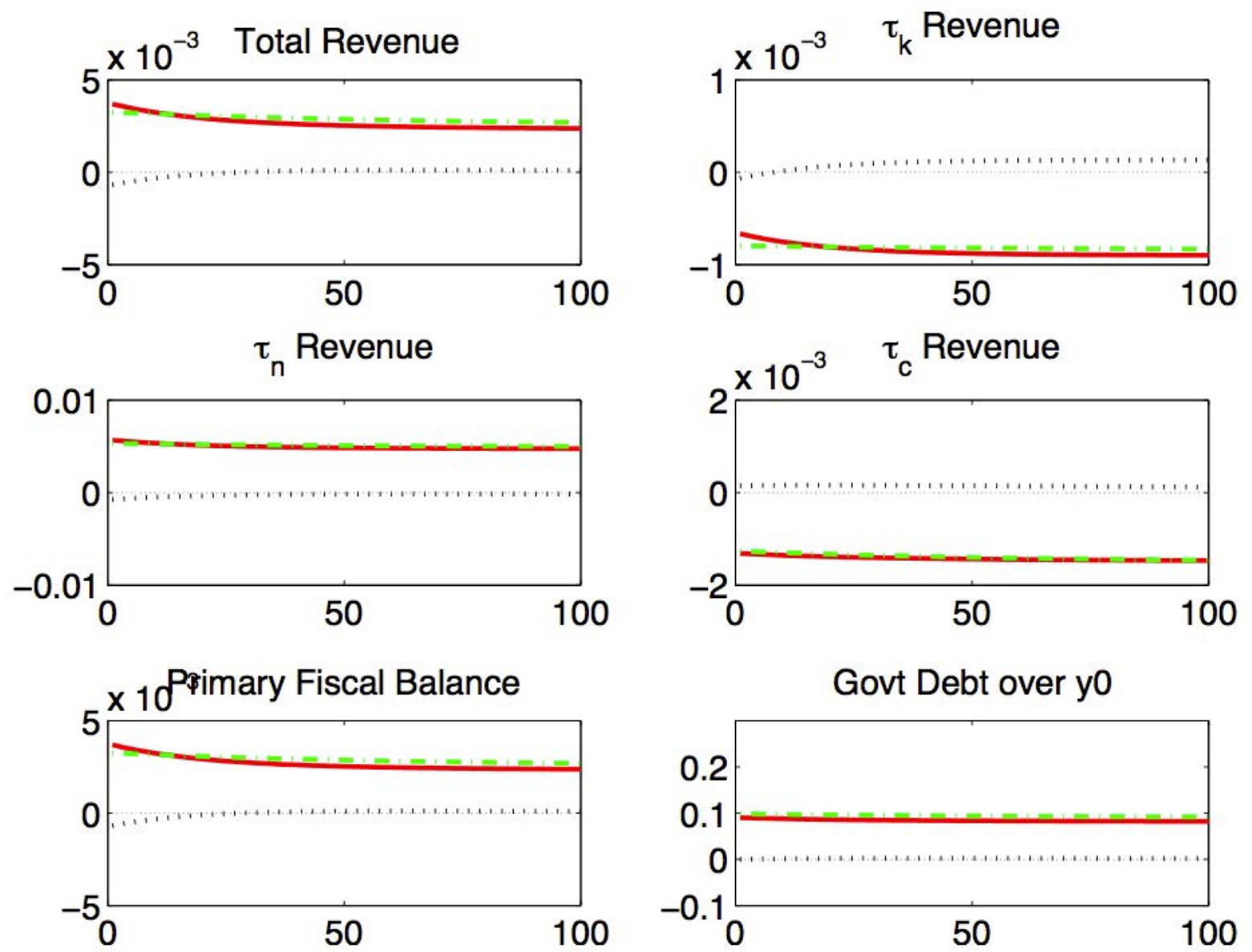

Notes: All variables are reported as changes from pre-crisis steady state levels. The solid red lines and the dotted black lines are for the home and foreign country, respectively, in the open economy. The dashed green lines are for the home country in the closed economy. 
Figure 9: Capital Tax Reaction Functions: Symmetric Game

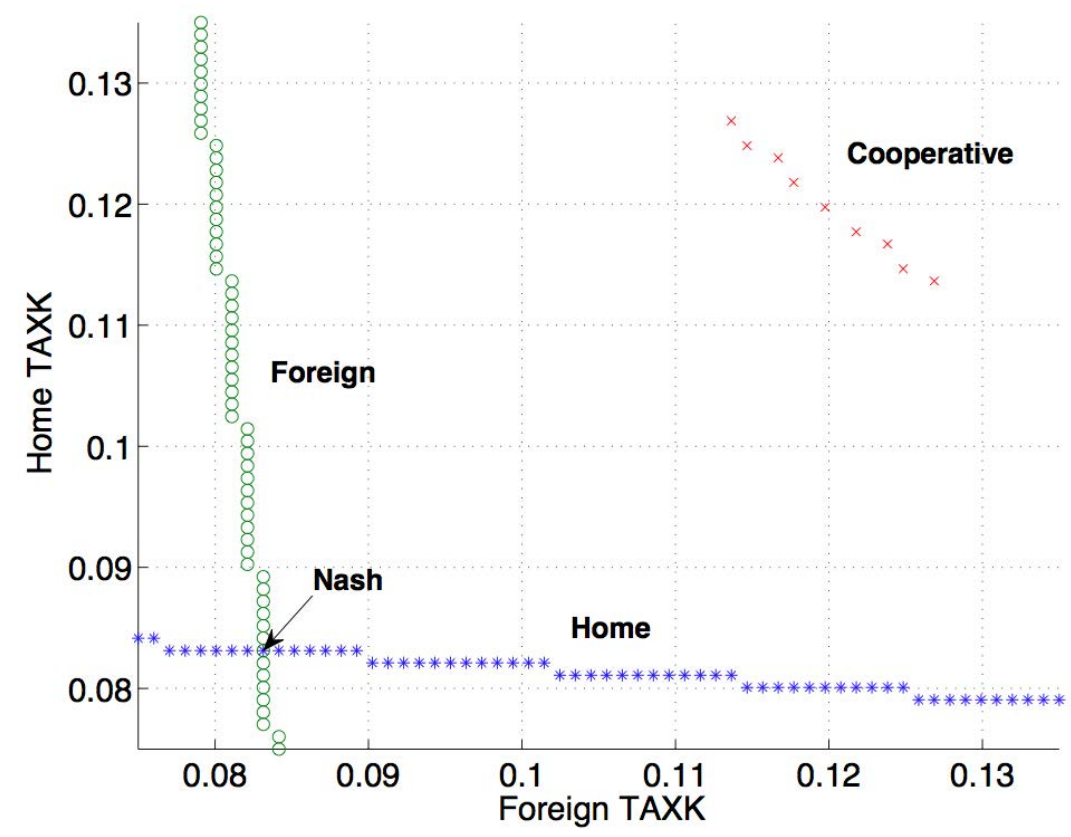

Figure 10: Capital Tax Reaction Functions: Asymmetric Game

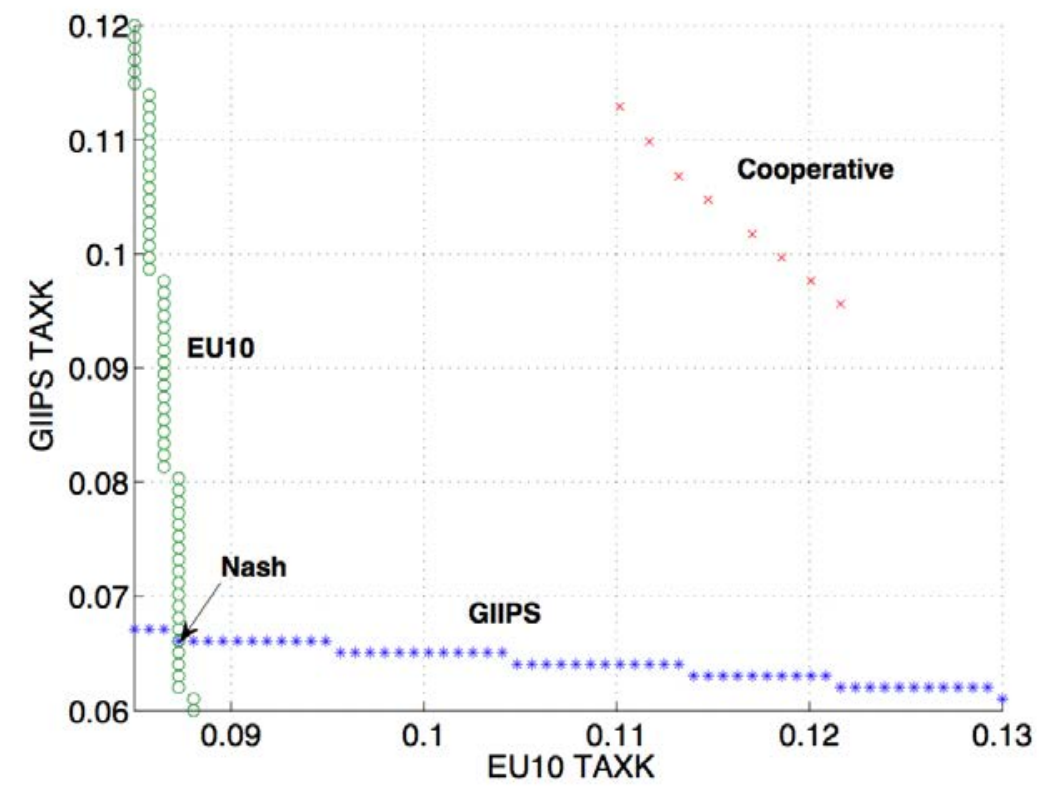




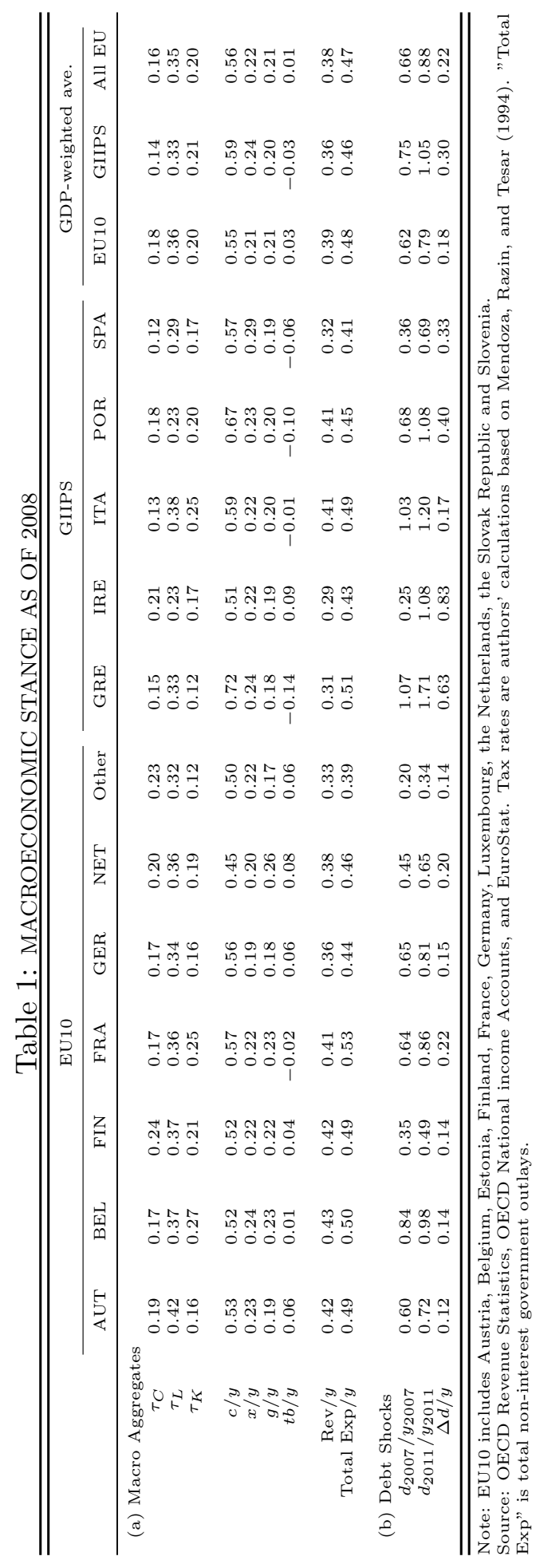




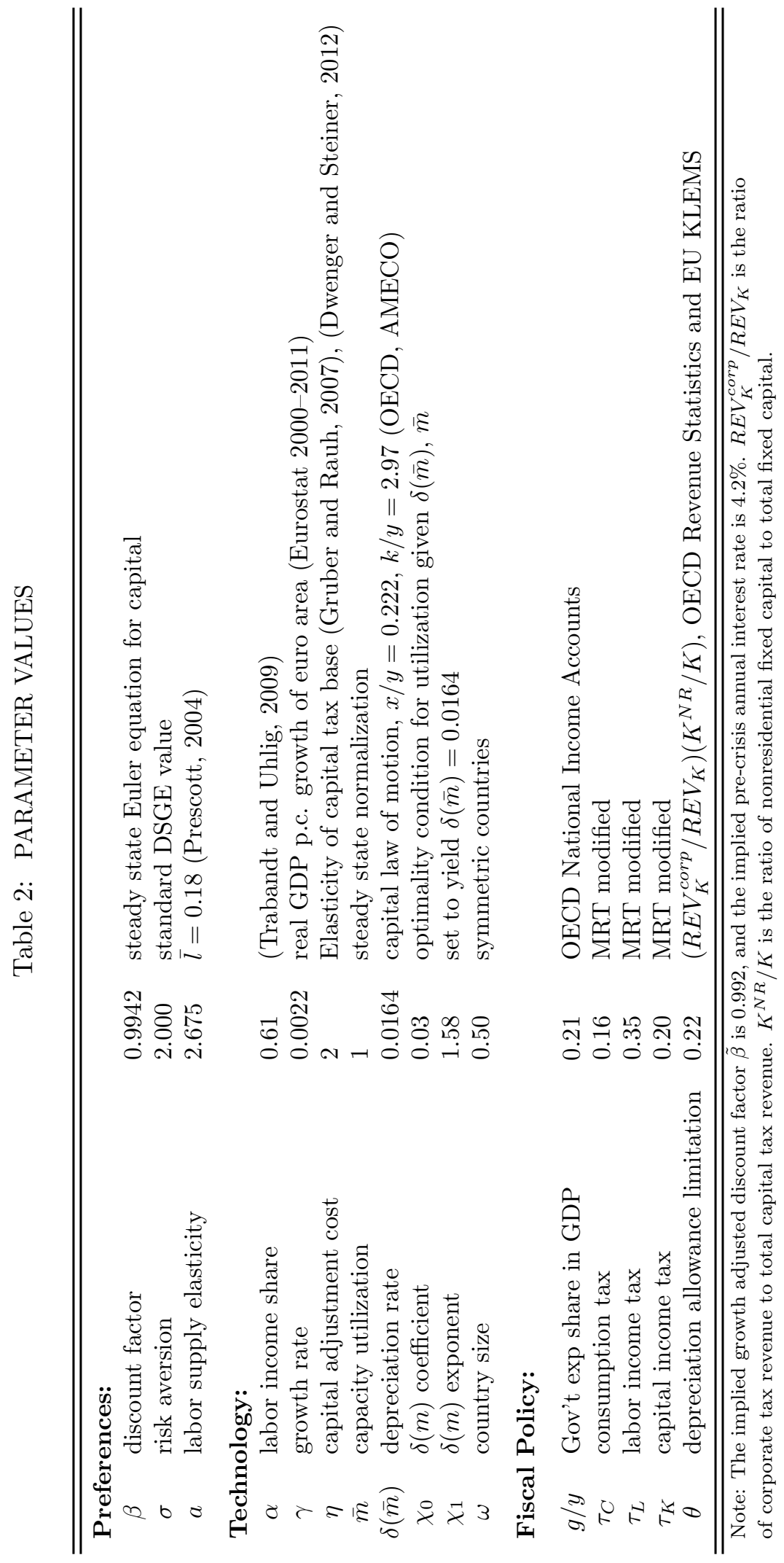


Table 3: BALANCED GROWTH ALLOCATIONS (GDP RATIOS) OF 2008

\begin{tabular}{|c|c|c|c|c|c|c|}
\hline & \multirow{2}{*}{\multicolumn{2}{|c|}{$\begin{array}{c}\text { Symmetric Case } \\
\text { All EU }\end{array}$}} & \multicolumn{4}{|c|}{ Asymmetric Case } \\
\hline & & & \multicolumn{2}{|c|}{ GIIPS } & \multicolumn{2}{|c|}{ EU10 } \\
\hline & Data & Model & Data & Model & Data & Model \\
\hline$c / y$ & 0.56 & 0.57 & 0.59 & 0.60 & 0.55 & 0.54 \\
\hline$x / y$ & 0.22 & 0.22 & 0.24 & 0.22 & 0.20 & 0.23 \\
\hline$g / y^{*}$ & 0.21 & 0.21 & 0.20 & 0.20 & 0.21 & 0.21 \\
\hline$t b / y$ & 0.00 & 0.00 & -0.03 & -0.03 & 0.03 & 0.03 \\
\hline $\operatorname{Rev} / y$ & 0.38 & 0.38 & 0.36 & 0.36 & 0.39 & 0.39 \\
\hline$d / y^{*}$ & 0.66 & 0.66 & 0.75 & 0.75 & 0.62 & 0.62 \\
\hline
\end{tabular}




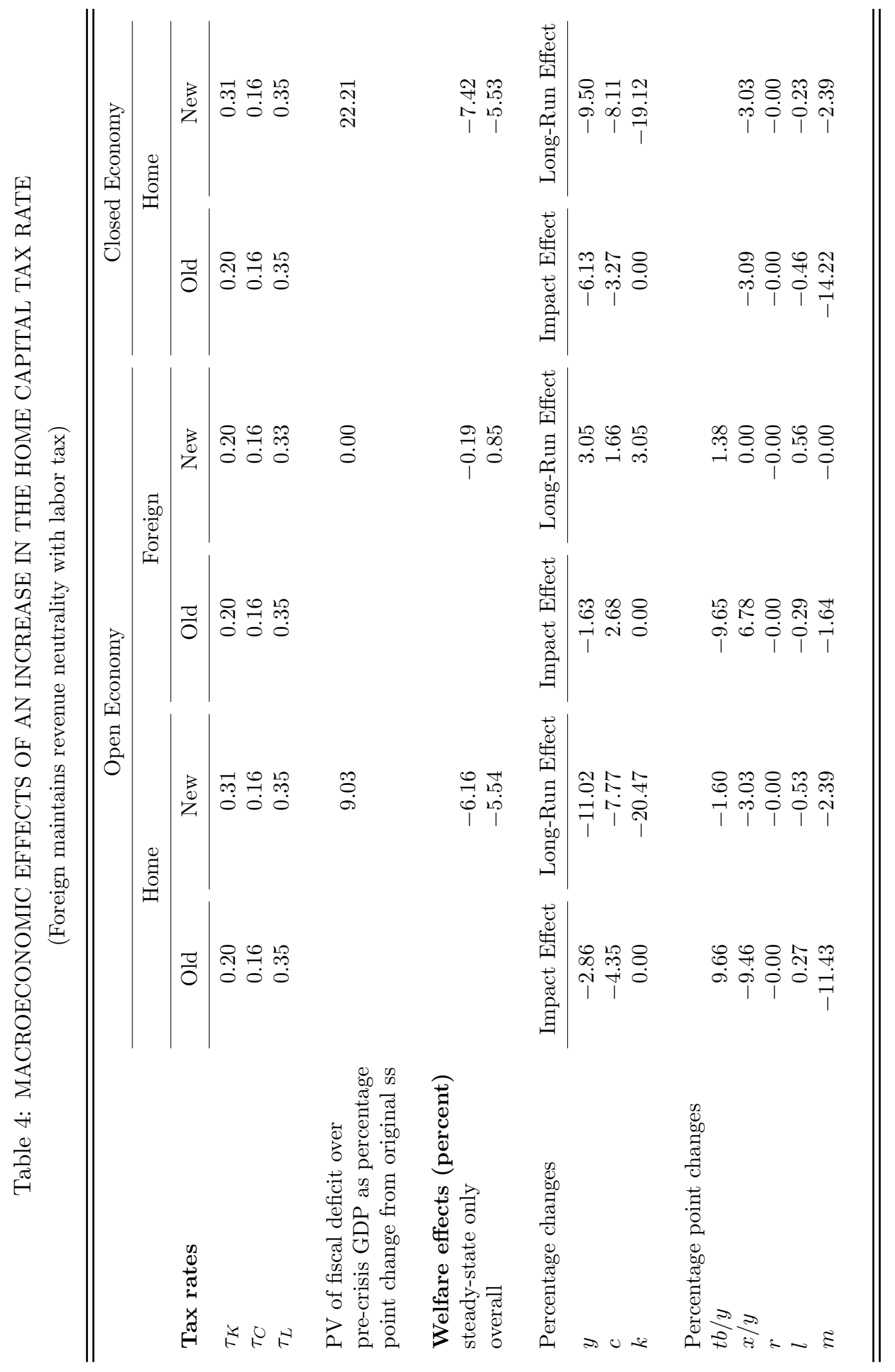




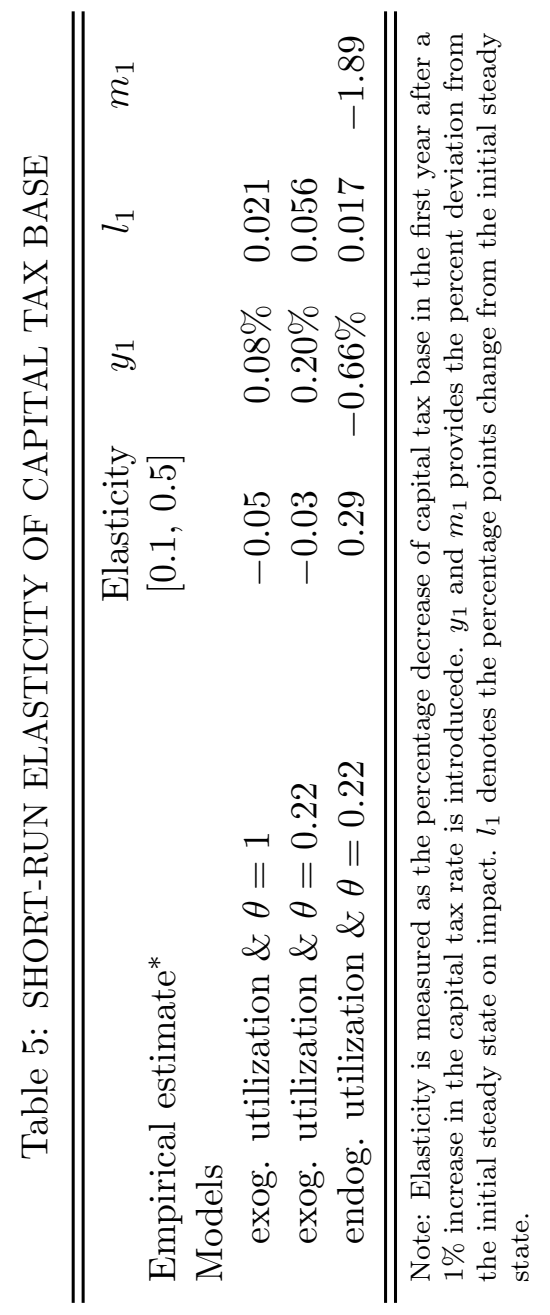




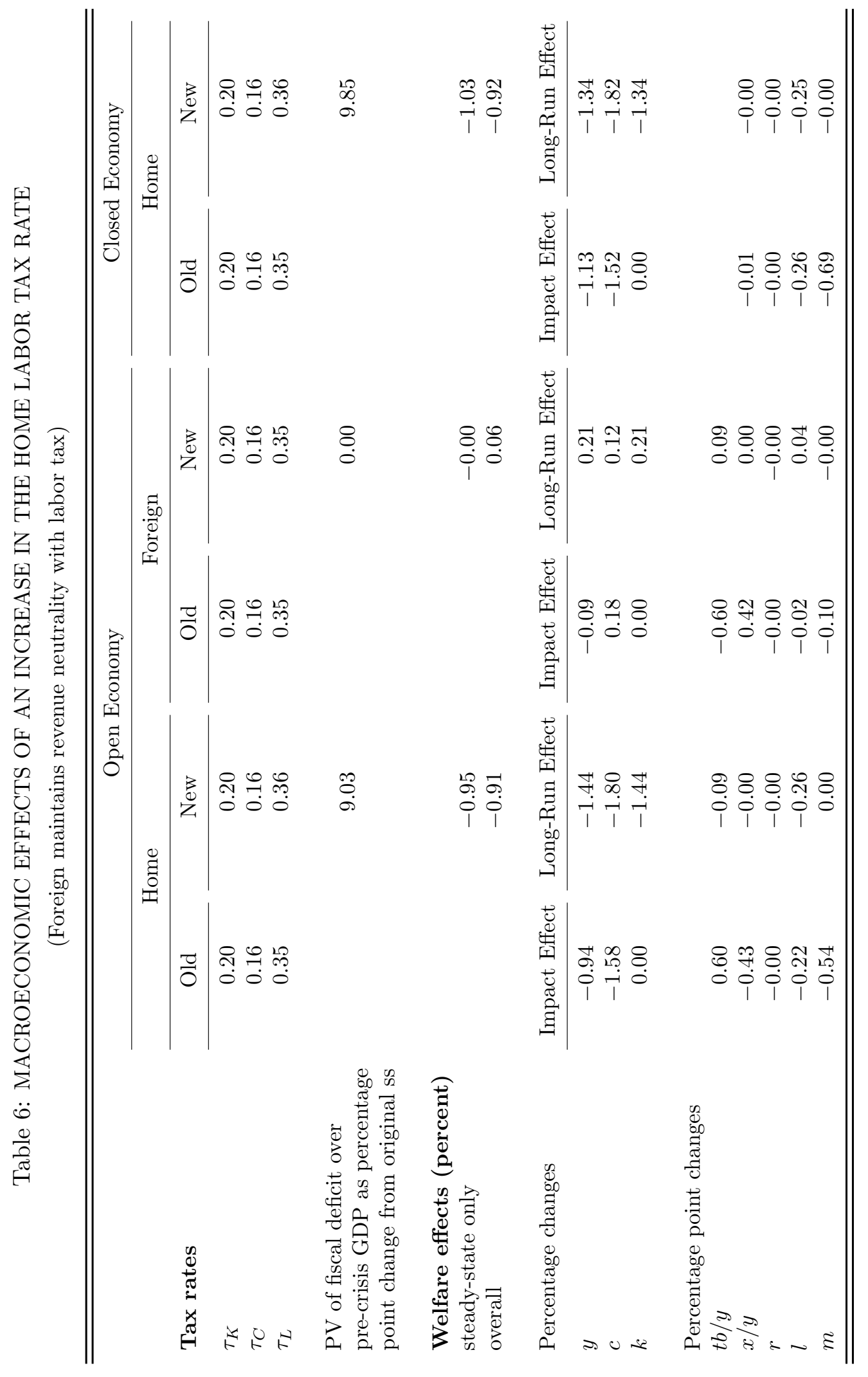




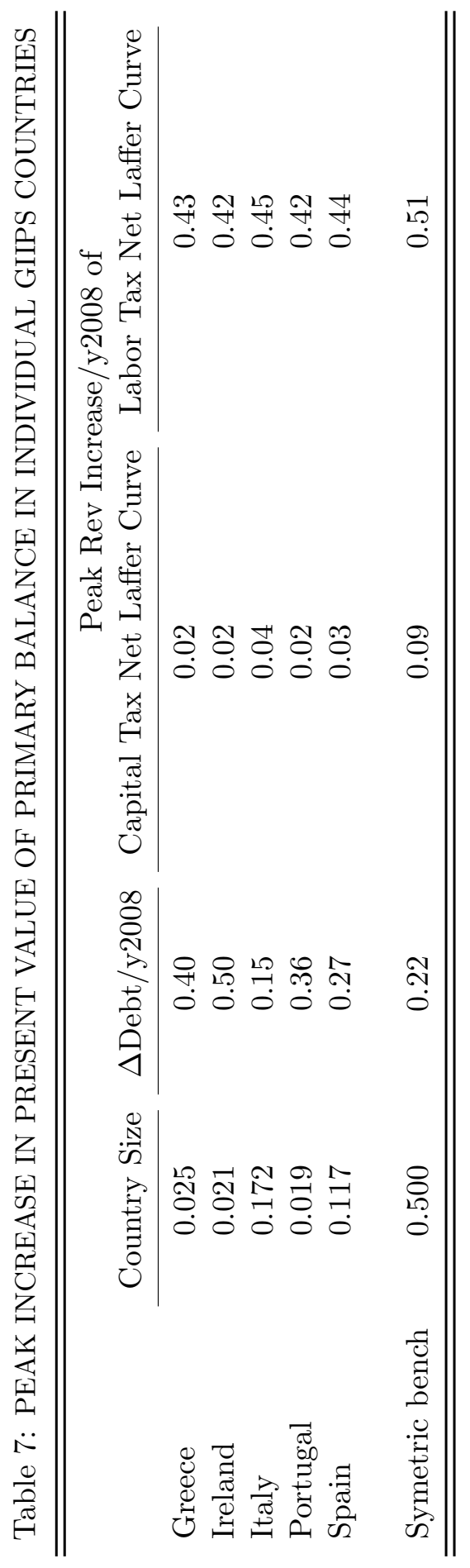


Table 8: SYMMETRIC-COUNTRY GAME OUTCOMES

\begin{tabular}{lrrrrrr}
\hline \hline & Pre-Crisis & Autarky & Unilateral & Cooperative & Nash & Neocl. Nash \\
\hline Home & & & & & & \\
$\tau_{K}$ & 0.202 & 0.121 & 0.077 & 0.121 & 0.083 & 0.138 \\
$\tau_{L}$ & 0.347 & 0.416 & 0.425 & 0.416 & 0.435 & 0.417 \\
$\quad \Delta$ PV(Primary Balance)/Y & & 0.222 & 0.222 & 0.222 & 0.222 & 0.222 \\
$\quad \Delta$ Welfare v. pre-crisis & & -1.448 & -0.674 & -1.448 & -1.627 & -2.709 \\
& & & & & & \\
Foreign & 0.202 & 0.121 & 0.202 & 0.121 & 0.083 & 0.138 \\
$\quad \tau_{K}$ & 0.347 & 0.416 & 0.358 & 0.416 & 0.435 & 0.417 \\
$\tau_{L}$ & & 0.222 & 0 & 0.222 & 0.222 & 0.222 \\
$\quad$ PV(Primary Balance)/Y & & -1.448 & -0.584 & -1.448 & -1.627 & -2.709 \\
$\Delta$ Welfare v. pre-crisis & & & & & & \\
& & & & & & \\
\hline \hline
\end{tabular}

Note: In the Nash game, the home and foreign countries both have the debt shock of 0.22 . We assign equal weights for the two countries in the cooperative equilibrium. For the unilateral experiment, the foreign country keeps its pre-crisis capital tax rate and adjusts its labor tax rate to maintain revenue neutrality, while the home country chooses its capital and labor tax rate which maximizes its welfare subject to the debt requirement. In the neoclassical experiment, capacity utilization is exogenous and $\theta$ is set at 0.22 .

Table 9: ASYMMETRIC-COUNTRY NASH GAME OUTCOMES

\begin{tabular}{|c|c|c|c|c|c|c|c|c|}
\hline & \multirow{2}{*}{$\begin{array}{c}\text { Symmetric } \\
\text { Bench }\end{array}$} & \multicolumn{7}{|c|}{ Asymmetric } \\
\hline & & Size & NFA & $\tau_{K}$ & $\tau_{L}$ & $\tau_{C}$ & Debt & All \\
\hline \multicolumn{9}{|l|}{ GIIPS } \\
\hline$\tau_{K}$ & 0.083 & 0.070 & 0.109 & 0.080 & 0.064 & 0.073 & 0.099 & 0.066 \\
\hline$\tau_{L}$ & 0.435 & 0.438 & 0.445 & 0.436 & 0.417 & 0.433 & 0.452 & 0.435 \\
\hline$\Delta \mathrm{PV}($ Primary Balance $) / \mathrm{Y}$ & 0.222 & 0.222 & 0.222 & 0.222 & 0.222 & 0.222 & 0.300 & 0.300 \\
\hline$\Delta$ Welfare v. pre-crisis & -1.627 & -1.438 & -3.245 & -1.261 & -0.603 & -1.015 & -3.503 & -1.549 \\
\hline \multicolumn{9}{|l|}{ EU 10} \\
\hline$\tau_{K}$ & 0.083 & 0.096 & 0.064 & 0.080 & 0.102 & 0.094 & 0.073 & 0.088 \\
\hline$\tau_{L}$ & 0.435 & 0.431 & 0.431 & 0.435 & 0.454 & 0.439 & 0.426 & 0.436 \\
\hline$\Delta \mathrm{PV}($ Primary Balance $) / \mathrm{Y}$ & 0.222 & 0.222 & 0.222 & 0.222 & 0.222 & 0.222 & 0.180 & 0.180 \\
\hline$\Delta$ Welfare v. pre-crisis & -1.627 & -1.698 & -0.703 & -1.594 & -2.985 & -2.318 & -0.589 & -1.127 \\
\hline
\end{tabular}

Note: In the first six asymmetric experiments, we incorporate only one cross-country difference each time. For the size experiment, we set $\omega$ to match the relative size between GIIPS and EU10. For the NFA experiment, we set the GIIPS pre-crisis current account as a share of GDP at the observed level of $-3 \%$. In each of the three asymmetric tax experiments, we allow the corresponding precrisis tax rates to vary across the two countries as in the data. Under the "Debt" column, we feed in the observed debt shocks for each country. Under the "All" column, we incorporate all the above cross-country differences. 
Table 10: GIIPS-EU10 GAME OUTCOMES

\begin{tabular}{|c|c|c|c|c|c|c|}
\hline & \multirow{2}{*}{ Pre-Crisis } & \multirow{2}{*}{ Autarky } & \multirow{2}{*}{ Unilateral } & \multicolumn{2}{|c|}{ Cooperative } & \multirow{2}{*}{ Nash } \\
\hline & & & & Case 1 & Case 2 & \\
\hline \multicolumn{7}{|l|}{ GIIPS } \\
\hline$\tau_{K}$ & 0.210 & 0.095 & 0.057 & 0.095 & 0.112 & 0.066 \\
\hline$\tau_{L}$ & 0.330 & 0.415 & 0.420 & 0.417 & 0.414 & 0.435 \\
\hline$\Delta \mathrm{PV}($ Primary Balance $) / \mathrm{Y}$ & & 0.300 & 0.300 & 0.300 & 0.300 & 0.300 \\
\hline$\Delta$ Welfare v. pre-crisis & & -1.032 & -0.410 & -1.238 & -1.546 & -1.549 \\
\hline \multicolumn{7}{|l|}{ EU10 } \\
\hline$\tau_{K}$ & 0.200 & 0.121 & 0.200 & 0.122 & 0.110 & 0.088 \\
\hline$\tau_{L}$ & 0.360 & 0.421 & 0.420 & 0.420 & 0.423 & 0.436 \\
\hline$\Delta \mathrm{PV}($ Primary Balance $) / \mathrm{Y}$ & & 0.180 & 0 & 0.180 & 0.180 & 0.180 \\
\hline$\Delta$ Welfare v. pre-crisis & & -1.197 & -0.511 & -1.120 & -0.924 & -1.127 \\
\hline Weights & & & & 0.31 & 0.23 & \\
\hline
\end{tabular}

Note: For the cooperative equilibrium, Case 1 reports the most favorable allocation to GIIPS within the core; Case 2 reports the results most favorable to EU10 within the core. 'Weights' report the social weight that the planner assigns to GIIPS to obtain Pareto improvements over the Nash outcome. The weight assigned to EU10 is '1-Weights'. For the unilateral experiment, the foreign country keeps its pre-crisis capital tax rate and adjusts its labor tax rate to satisfy the revenue neutrality, while the home country chooses its capital and labor tax rate which maximizes its welfare subject to the debt requirement. 